\title{
WestVirginiaUniversity
}

THE RESEARCH REPOSITORY @ WVU

Graduate Theses, Dissertations, and Problem Reports

2006

\section{Resistance to change of responding to stimulus relations}

\author{
Marta Leon \\ West Virginia University
}

Follow this and additional works at: https://researchrepository.wvu.edu/etd

\section{Recommended Citation}

Leon, Marta, "Resistance to change of responding to stimulus relations" (2006). Graduate Theses,

Dissertations, and Problem Reports. 2415.

https://researchrepository.wvu.edu/etd/2415

This Dissertation is protected by copyright and/or related rights. It has been brought to you by the The Research Repository @ WVU with permission from the rights-holder(s). You are free to use this Dissertation in any way that is permitted by the copyright and related rights legislation that applies to your use. For other uses you must obtain permission from the rights-holder(s) directly, unless additional rights are indicated by a Creative Commons license in the record and/ or on the work itself. This Dissertation has been accepted for inclusion in WVU Graduate Theses, Dissertations, and Problem Reports collection by an authorized administrator of The Research Repository @ WVU.

For more information, please contact researchrepository@mail.wvu.edu. 
Resistance to Change of Responding to Stimulus Relations

Marta León

\author{
Dissertation submitted to the \\ Eberly College of Arts and Sciences \\ at West Virginia University \\ in partial fulfillment of the requirements \\ for the degree of \\ Doctor of Philosophy \\ in \\ Psychology \\ Philip N. Chase, Ph.D., Chair \\ Karen Anderson, Ph.D. \\ Daniel Hursh, Ph.D. \\ B. Kent Parker, Ph.D. \\ Julie H. Patrick, Ph.D. \\ Department of Psychology
}

Morgantown, West Virginia

2006

Keywords: Resistance to Change, Behavioral Momentum, Stimulus Equivalence 


\section{ABSTRACT \\ Resistance to Change of Responding to Stimulus Relations}

\section{Marta León}

Three experiments assessed resistance to change of response accuracy under different reinforcement rates. Fifteen college students responded to a matching-to-sample task, with one set of baseline conditional relations reinforced at a rich rate and another set reinforced at a lean rate. In two experiments, resistance to change was assessed by presenting tests for emergent equivalence relations and then reversing some of the baseline conditional discriminations and examining changes in the equivalence classes after the reversal; the experiments differed in the presence or absence of overtraining for the rich condition. The third experiment assessed resistance to change by testing for emergent equivalence relations and then requiring participants to respond to distracting stimuli during the matching-to-sample task. Retention after two weeks was measured in the three experiments. The rich reinforcement rate resulted in faster emergence of equivalence responding and greater resistance to distraction only when accompanied by overtraining. The rich reinforcement rate resulted in responding that was more resistant to the reversal of baseline relations for participants who had partial class reversals, but not for participants who had complete class reversals. Furthermore, partial reversals occurred more often when overtraining was minimized or eliminated. There were no systematic differences in retention for the rich and lean conditions in any of the experiments. Findings are discussed in terms of the degree of integration of equivalence classes and the use of conditioned reinforcement to study behavioral momentum in humans. 


\section{Table of Contents}

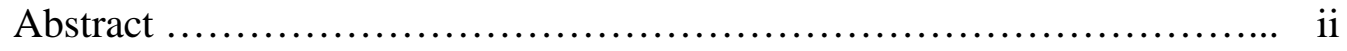

Table of Contents .............................................. iii

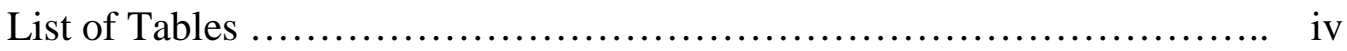

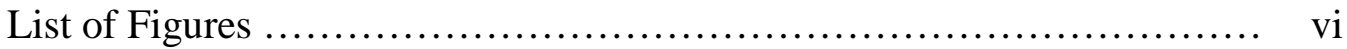

Resistance to Change of Responding to Stimulus Relations ............... 1

Statement of the Problem .......................................... 6

Experiment 1 .................................................... 7

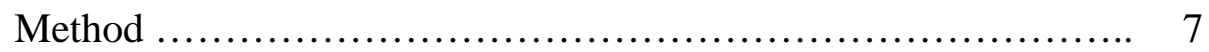

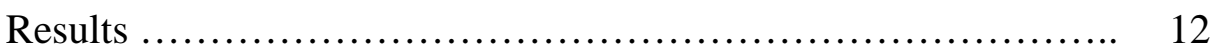

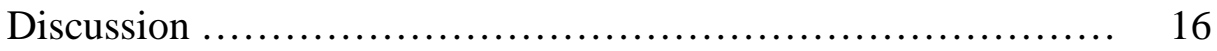

Experiment 2 .................................................. 21

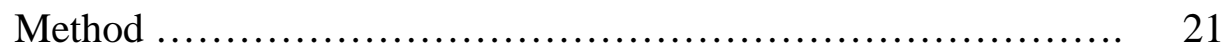

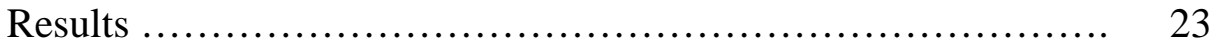

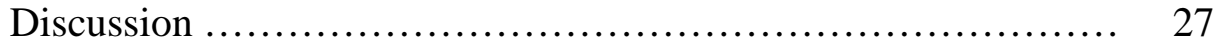

Experiment 3 .............................................. 33

Method ............................................. 33

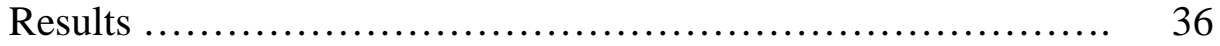

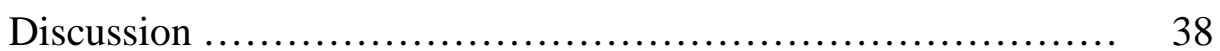

General Discussion ......................................... 42

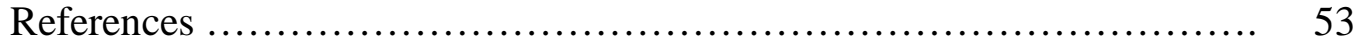

Tables ................................................... 59

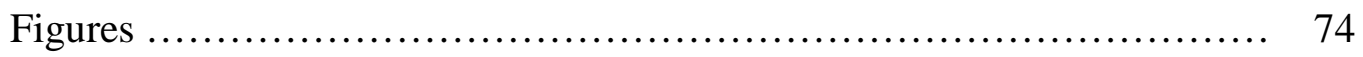

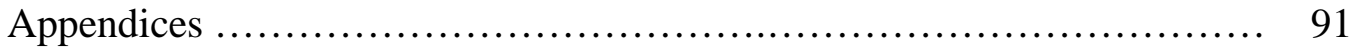




\section{List of Tables}

Table 1. Stages of Experiments 1 and 2.

Table 2. Composition of Blocks and Trials for Training and Equivalence Testing of Experiments 1 and 2.

Table 3. Composition of Blocks and Trials for Reversal Training and Post-reversal Tests of Experiments 1 and 2.

Table 4. Number of Blocks Needed to Reach Mastery Criteria in AB and BC training for Each Experimental Condition in Experiment 1.

Table 5. Mean Response Speeds to Correct and Incorrect Comparison Stimuli during the First Two Blocks of Initial Testing for Experiment 1.

Table 6. Number of Blocks to Criterion for Reversal Training for Experiment 1.

Table 7. Mean Response Speeds to Correct and Incorrect Comparison Stimuli during the First Two Blocks of Reversal Training for Experiment 1.

Table 8. Mean Response Speeds to Correct and Incorrect Comparison Stimuli during the First Two Blocks of Post-Reversal Tests for Experiment 1.

Table 9. Response Speeds to Correct and Incorrect Comparison Stimuli during the First Two Blocks of Retention Tests for Experiment 1.

Table 10. Number of Blocks Needed to Reach Mastery Criteria in AB and BC training for Each Experimental Condition in Experiment 2.

Table 11. Amount of overtraining in the $\mathrm{AB}$ and $\mathrm{BC}$ training conditions in Experiment 2.

Table 12. Mean Response Speeds to Comparison Stimuli for Correct and Incorrect Trials during the First Two Blocks of Initial Testing for Experiment 2. 
Table 13. Number of Blocks Needed to Reach Mastery Criteria for Each Condition during

Reversal Training for Experiment 2.

Table 14. Mean Response Speeds to Correct and Incorrect Comparison Stimuli during the First

Two Blocks of Reversal Training for Experiment 2.

Table 15. Mean Response Speeds to Correct and Incorrect Comparison Stimuli during the First

Two Blocks of Post-reversal Tests for Experiment 2.

Table 16. Mean Response Speeds to Comparison Stimuli for Correct and Incorrect Trials during the First Two Blocks of Retention Tests for Experiment 2.

Table 17. Stages of the Experimental Design for Experiment 3.

Table 18. Number of Trials per Block for Each Trained and Tested Conditional Relation at Each

Stage of Baseline Training and During Testing in Experiment 3.

Table 19. Number of Blocks Needed to Reach Mastery Criteria during Training for Each

Experimental Condition in Experiment 3.

Table 20. Mean Response Speeds to Comparison Stimuli in Correct Trials during the Last Block of Training in Experiment 3.

Table 21. Mean Response Speed to Comparison Stimuli during the First Two Blocks of Equivalence Tests Separated by Nodal Distance for Experiment 3.

Table 22. Accuracy Levels for Baseline Training and Disruption Training Across Conditions for Experiment 3.

Table 23. Response Speeds for the Last Block of Baseline Training and the First Block of Disruption Training Across Conditions for Experiment 3.

Table 24. Mean Response Speeds for Correct and Incorrect Trials during the First Two Blocks of Retention Tests. 


\section{List of Figures}

Figure 1. Stimuli used in Experiments 1 and 2.

Figure 2. Percent accuracy on all test trials during the first two blocks of initial tests for each participant and condition for Experiment 1.

Figure 3. Percent accuracy on transitivity and combined tests during the first two blocks of testing for each condition and each participant in Experiment 1.

Figure 4. Percent class-consistent responding in the first two blocks of post-reversal tests for participants 184, 221, and 788 in Experiment 1.

Figure 5. Percent class-consistent responding in the first two blocks of post-reversal tests for participants 300, 311, and 425 in Experiment 1.

Figure 6. Percent class-consistent responding in the first two blocks of retention tests for participants 184, 221, and 788 in Experiment 1.

Figure 7. Percent class-consistent responding in the first two blocks of retention tests for participants 300, 311, and 425 in Experiment 1.

Figure 8. Percent accuracy on all test trials during the first two blocks of initial testing for each participant in Experiment 2.

Figure 9. Percent class-consistent responding during the first two blocks of post-reversal tests for participants 522, 556, 854, and 987 in Experiment 2.

Figure 10. Percent class-consistent responding during the first two blocks of post-reversal tests for participants 147 and 633 in Experiment 2.

Figure 11. Percent class-consistent responding during the first two blocks of retention tests for participants 522 and 854 in Experiment 2. 
Figure 12. Percent class-consistent responding during the first two blocks of retention tests for participants 556 and 633 in Experiment 2.

Figure 13. Percent class-consistent responding during the first two blocks of retention tests for participants 147 and 987 in Experiment 2.

Figure 14. Stimulus sets and classes used in Experiment 3.

Figure 15. Distracting stimuli used in Experiment 3.

Figure 16. Percent accuracy during the first two blocks of testing for each type of relation for Experiment 3.

Figure 17. Response speed during the first block of training disruption expressed as proportion of the last block of baseline training in Experiment 3.

Figure 18. Accuracy during the first block of testing disruption expressed as proportion of the last block of initial testing in Experiment 3.

Figure 19. Percent accuracy during retention tests across conditions by type of relation for Experiment 3. 


\section{Resistance to Change of Responding to Stimulus Relations}

Resistance to change of responding is demonstrated when a response pattern is maintained in the face of conditions that typically produce disruptions in responding. Resistance to change is greater for responses that have been reinforced at higher rates than for responses that have been reinforced at lower rates (Mace et al., 1990; Nevin, Mandell, \& Atak, 1983). That is, when a behavioral disruptor is applied, the response pattern of the former is less disrupted than the response pattern of the latter. Resistance to change has been tied theoretically to response strength or behavioral momentum, which compares the momentum of behavior to the momentum of bodies in motion as described in physics (Nevin et. al, 1983). In physics, the momentum of a body in motion refers to the degree to which an opposing force will alter the body's velocity, and a body's momentum is determined by the product of the body's mass and velocity. In the behavioral analogy proposed by Nevin et al., the momentum of a response is determined by the product of its response rate (velocity) and its reinforcement rate (mass). A response with great momentum would be less altered by the presentation of a behavioral disruptor than a response with less momentum. Behavioral momentum, then, is a relative property of behavior and can be assessed by comparing the resistance to change of one response with the resistance to change of a different response or the same response under a different discriminative stimulus (Nevin et al., 1983).

Most studies on the relation between reinforcement rate and resistance to change have focused on time-based measures such as response rate (e.g., Dube \& McIlvane, 2001; Mace et al., 1990) and response latency (e.g., Belfiore, Lee, Vargas, \& Skinner, 1997), while the effects of reinforcement rate on other measures of behavior have not received the same amount of attention. It has been noted, however, that if reinforcement rate has a strengthening effect on 
responding, then other parameters of responding besides response rate should also be affected by reinforcement rate (Nevin, Milo, Odum, \& Shahan, 2003).

One such parameter of responding that can be strengthened by reinforcement rate is response accuracy (Nevin et al., 2003). The behavioral momentum of response accuracy has multiple and relevant implications for research and interventions in applied settings. For example, acceptable performance on academic tasks is largely dependent on the accuracy levels that students are able to achieve. In fact, accuracy is one of the critical features that distinguish the performance of experts from that of individuals considered less accomplished at a particular task (Ericsson, Krampe, \& Tesch-Romer, 1993). Some authors have maintained that high accuracy levels are a prerequisite for building a fluent response repertoire, which is purportedly a necessary condition for remembering and applying skills to novel situations (Johnson \& Layng, 1992). The importance of high levels of accuracy is especially salient in the fields of reading and mathematics where recombination of basic skills into more complex repertoires is necessary throughout all the levels of formal education (Cooke \& Guzaukas, 1993). In summary, high accuracy levels appear to be a prerequisite for applying a particular skill to novel or complex situations. Therefore, variables affecting accuracy on basic skills could prove useful in enhancing performance in terminal-level skills.

Variables affecting accuracy on different tasks have been examined and include practice (Ericsson et al., 1993), feedback (Cinciripini, Epstein, \& Martin, 1979; Dihoff, Brosvic, Epstein, \& Cook, 2004), and building high rates of responding (Young, West, Howard, \& Whitney, 1986). It has been noted, however, that purported effects of building high rate of responding may be confounded with reinforcement rate (Doughty, Chase, \& O'Shields, 2004). The investigation of reinforcement rate as a variable affecting response accuracy, thus, is relevant both in terms of 
the theory of behavioral momentum and for explaining findings from other areas of research such as response rate building.

Three studies of behavioral momentum have reported measuring response accuracy as the main dependent variable. Nevin et al. (2003) examined the effects of reinforcement rate on both response rate and accuracy of discrimination in pigeons. Pigeons were trained on a multiple chained schedule whose components ended in matching-to-sample trials. These conditional discrimination trials involved matching a diagonal line comparison to a diagonal line sample and matching a vertical line comparison to a vertical line sample. Correct discriminations were reinforced with a probability of .80 in one component (rich) and .20 in the other component (lean). When discriminations reached a stable accuracy level, resistance to change was assessed while introducing disruptors such as prefeeding, response-independent food presentation, insertion of a delay interval between sample and comparison stimuli, and extinction. As predicted by the behavioral momentum theory, response rates were higher for the rich component than for the lean component during each of the disruption conditions. More important for the purpose of the present study, the accuracy of discrimination during the rich component remained at higher levels than the accuracy of discrimination during the lean component for all the disruption conditions. Based on these results, the authors concluded that the accuracy of discrimination responses is strengthened by reinforcement in a similar pattern as response rate is.

Although Nevin et al. (2003) obtained consistently greater resistance to change of accuracy on discriminations maintained by a rich rather than a lean schedule, comparable results have not been found in research with human participants. For example, Dube and McIlvane (2001) trained participants with developmental disabilities on two discrete trial discrimination tasks using continuous reinforcement (rich condition). When participants reached high accuracy 
levels, the reinforcement schedule for one of the tasks changed to an intermittent reinforcement schedule (lean condition). Then, probe sessions presented three behavioral disruptors: presession feeding, response-independent reinforcement, and the opportunity to engage in an alternative, reinforcing activity. Dube and McIlvane found no consistent differences in accuracy across the two tasks. As the authors pointed out, however, the tasks performed by the participants were purposely chosen to result in high levels of accuracy in order to minimize errors. Therefore, the tasks were relatively low-level -a simple discrimination task and a two-comparison identity matching-to-sample task. Furthermore, Dube and McIlvane initially used continuous reinforcement as the schedule for both experimental tasks before changing the reinforcement schedule for one of the tasks to a variable-ratio schedule. It is possible that this initial training with identical reinforcement schedules was responsible for the lack of differences in accuracy across tasks.

In a second study, Dube and McIlvane (2002) trained nine participants with mental retardation in two, two-choice simple discrimination tasks. For one of the tasks, correct responding was reinforced on a continuous reinforcement (rich) schedule; for the other task, correct responding was initially reinforced continuously, but after response acquisition the reinforcement schedule was changed to an intermittent schedule (lean). After participants reached stable accuracy levels, reversal training was introduced in which selecting the previously trained correct stimulus was no longer reinforced in either of the two discrimination tasks, whereas selecting the previously incorrect stimulus was reinforced on a continuous schedule for both tasks. Error rates during reversal training were measured as the primary indicator of resistance to change. The results were consistent with the behavioral momentum prediction: during reversal training, participants made more errors in the discrimination task maintained by 
the rich schedule than in the task maintained by the lean schedule, showing that the former was more resistant to change than that of the latter.

The absolute number of errors made by participants in the Dube and McIlvane (2002) study, however, was small (maximum three), and five out of nine participants did not make any errors in any of the conditions. This small range of errors, or ceiling effect, does not allow for a strong comparison of the differential effects of reinforcement rate on accuracy. In this case, as in the Dube and McIlvane (2001) study, the low level of skill required by the experimental task may have been responsible for relatively high accuracy that was maintained even in the leanreinforcement condition.

Furthermore, the question remains whether different reinforcement rates can result in differential accuracy under disruption conditions for tasks that require application of trained responses to novel situations. Examining how reinforcement rate influences untrained responding is relevant to further understand how accuracy on trained responses facilitates application to new situations (cf. Johnson \& Layng, 1992). Furthermore, the requirement to respond to untrained relations has been considered a test of resistance to change per se because of the changed contingencies that prevail when testing for these untrained relations (Dube \& McIlvane, 1996). To the extent of the experimenter's knowledge, no previous studies have examined how different reinforcement rates during training affect performance on related but untrained behavior. For example, Nevin et al. (2003) assessed the resistance to change of discriminations that were invariable throughout training and testing. Similarly, Dube and McIlvane (2001, 2002) examined the resistance to change of discriminations that were directly trained. 
One task that requires application of trained behavior to novel situations is stimulus equivalence (Chase, 2003). Stimulus equivalence responding is demonstrated when, after training on arbitrary conditional relations among stimuli, participants respond to relations among stimuli that meet the criteria of equivalence without explicit training. For example, after being trained to select stimulus B in the presence of stimulus $\mathrm{A}$, and to select stimulus $\mathrm{C}$ in the presence of stimulus B, if participants select stimulus A in the presence of B and B in the presence of $\mathrm{C}$ (symmetry relations); stimulus $\mathrm{C}$ in the presence of $\mathrm{A}$ (transitivity relation); and stimulus $\mathrm{A}$ in the presence of $\mathrm{C}$ (combined symmetry and transitivity relation) without explicit training, then equivalence has been established and A, B, and C form a stimulus class (Barnes, Smeets, \& Leader, 1996). Because responding to tests of equivalence is a robust phenomenon in verbal human participants, it may serve as a good test of the effects rate of reinforcement on the application of trained behavior to novel situations.

\section{Statement of the Problem}

Although one study with pigeons has shown effects of rate of reinforcement on accuracy consistent with behavioral momentum, experiments with human participants have revealed only a weak relation between rate of reinforcement and accuracy. The results of Dube and McIlvane (2002) are promising in suggesting that reinforcement rate affects the resistance to change of accuracy of human responding, but the relatively small effects prevent firm conclusions about the robustness of the effect. If lower-level skills such as simple discriminations tend to result in high accuracy of responses even in conditions of lower reinforcement rate, then differences among rates of reinforcement might be best studied with higher-level skills, such as responding to equivalence relations, which are less likely to result in ceiling effects. 
The purpose of the present study was twofold. First, it assessed the relation between reinforcement rate and response accuracy on trained conditional relations as a systematic replication of previous studies. The procedures varied from Dube and McIlvane (2002) in a number ways in an attempt to increase the differences between the rich and lean reinforcement rates. Second, the current study assessed the effects of reinforcement rate on tests for stimulus equivalence to determine whether the accuracy of untrained behavior that requires application of learned behavior to novel situations is also predicted by behavioral momentum theory. If behavioral momentum theory is applicable to the accuracy of equivalence responding, then behavior that has been trained with a rich reinforcement rate should yield novel responding that is more accurate under disruption than behavior that has been trained with a lean reinforcement rate.

\section{EXPERIMENT 1}

Method

\section{Participants}

Seven female undergraduate students (ages 18 to 20) participated in this experiment. One participant who failed to perform above chance levels in the initial tests for stimulus equivalence was dismissed from the experiment and her data excluded from analysis. Participants were recruited from an introductory course in psychology and paid for attending sessions and for their performance on the experimental tasks. Selection criteria required that participants had not taken any course in advanced mathematics or in behavioral principles.

\section{Apparatus and Setting}

Instructions, tasks, and experimental contingencies were programmed in Microsoft Visual Basic 6.0 and presented on an IBM-compatible, Pentium $4533 \mathrm{MHZ}$ computer. The 
stimulus array consisted of a sample stimulus located on the center of the computer monitor and three comparison stimuli located under the sample at equal distances from each other.

Experimental sessions took place in a room approximately $3 \mathrm{~m}^{2}$ equipped with the computer, a desk, a chair, and a one-way mirror connecting to the experimenter room. A white-noise generator was used to mask external noise.

Design

Table 1 shows the basic design of the experiment and details for each condition are presented below. A within-subject design was used in which two conditions consisted of responding to stimulus classes maintained by different reinforcement rates. Responding to each condition was trained in blocks that alternated within each session. Participants were trained in the baseline relations in each condition and then tested for equivalence relations. A disruption condition was conducted to assess resistance to change, followed by retention tests after two weeks.

Procedure

Stimuli. Participants were trained in two sets of three stimulus classes with each class consisting of three stimuli. Each stimulus set was associated with one reinforcement rate condition, and the relation between a stimulus set and a reinforcement rate condition was counterbalanced across participants. Figure 1 shows the stimuli within each stimulus set. When referring to stimuli throughout this document, letters indicate sets of sample stimuli and numbers indicate the stimulus classes. These letter/number combinations are paired with other combinations, with the first being the sample and the second being the comparison. Thus, A1B1 refers to A1 as sample and B1 as the correct comparison. These letters and numbers were not shared with the participants. 
Baseline training. The following instructions were presented prior to training.

Your job in this study is to learn which symbols belong in the same group. When a symbol is presented on the screen, click on it to see the symbols that could be in the same group as the first symbol. Then, click on the symbol that you believe belongs in the same group as the first symbol. The number of points you earn will depend on your ability to identify which symbols belong together. Press the button below when you are ready to begin.

A simultaneous matching-to-sample (MTS) procedure was used to train the baseline relations. At the beginning of a trial, a delay ranging from zero to three seconds preceded the presentation of the sample stimulus (cf. Carlin, Wirth, \& Chase, 1998). After the delay, a click on the sample displayed three comparison stimuli underneath it. Selecting the experimenterdesignated comparison (correct responding) resulted in the word "Correct" displayed on the screen for one second, earning one point worth 3.5 cents, and the initiation of a one-second intertrial interval. Selecting a comparison other than the experimenter-designated correct comparison (incorrect responding) was followed by of the word "Wrong" displayed on the screen for one second and the termination of the trial followed by the a new trial.

Responding was followed by performance feedback provided at different rates. In one condition (rich), responding was followed by performance feedback according to a variable-ratio 2 (VR 2) schedule. In the VR 2 schedule, a consequence was presented after an average of two responses. After an average of two trials, participants received performance feedback based on the last response they made before feedback was scheduled: if the last response was correct, it was followed by reinforcement; if the last response was incorrect, it was followed by the 
correction message. In the other condition (lean), responding received feedback according to a variable-ratio 9 (VR 9) schedule in which after an average of nine trials feedback was delivered based on the accuracy of the last response.

Classes were trained linearly (i.e., A $\rightarrow$ B $\rightarrow$ C; Green \& Saunders, 1998) beginning with $\mathrm{AB}$ relations (A1B1, A2B2, and A3B3, shown in Figure 1). Training was organized in blocks of 36 trials, with each $\mathrm{AB}$ relation presented 12 times per block in random order, with the requirement that a relation was not presented more than two times in a row (see Table 2 for baseline trial composition).

When performance on the $\mathrm{AB}$ relations was $90 \%$ accurate in both the rich and lean conditions, training began for $\mathrm{BC}$ relations (B1C1, B2C2, and $\mathrm{B} 3 \mathrm{C} 3$ shown in Figure 1). Training the $\mathrm{BC}$ relations followed the same procedures as the $\mathrm{AB}$ relations and required performance to be $90 \%$ accurate before advancing to the next phase, in which trials of $\mathrm{AB}$ and $\mathrm{BC}$ relations were intermixed with an equal number of $\mathrm{AB}$ and $\mathrm{BC}$ trials in a block (see Table 2). An accuracy criterion of $90 \%$ correct performance on the combined $\mathrm{AB}$ and $\mathrm{BC}$ baseline relations was required for advancing to the next phase.

Tests of stimulus equivalence. This phase introduced blocks of trials assessing the formation of symmetry, transitivity, and combined relations. For each condition, two test blocks were presented and followed by one block of baseline trials. A typical session in this phase began with the following sequence: 1) one lean-condition test block, 2) one rich-condition test block, 3) one lean-condition test block, 4) one rich-condition test block, 5) one lean-condition baseline block, and 6) one rich-condition baseline block. Whether the first block corresponded to the lean or the rich condition was counterbalanced across participants. 
Test blocks consisted of 36 trials, each assessing BA symmetry, CB symmetry, AC transitivity, and CA combined relations for each of the three classes of a stimulus set. Symmetry trials were presented prior to transitivity and combined trials (Green \& Saunders, 1998). The bottom rows of Table 2 present test trial composition. No performance feedback followed performance on the test trials.

Baseline blocks consisted of 36 trials of $\mathrm{AB}$ and $\mathrm{BC}$ relations reinforced according to the same schedule used during baseline training -i.e. VR 2 for the rich condition and VR 9 for the lean condition. Two stability criteria had to be met before advancing to the next phase: performance on baseline blocks needed to be above $90 \%$ without increasing or decreasing trends, and performance on test blocks had to stay within $10 \%$ of the mean of the last two test blocks without increasing or decreasing trends.

Reversal training. Reversal training presented blocks of 36 trials with $\mathrm{AB}$ relations presented 12 times each. The relation between the A and B stimuli was reversed for classes 1 and 2 of each condition. That is, when A1 and A2 were the samples, the new correct comparisons were $\mathrm{B} 2$ and $\mathrm{B} 1$, respectively. AB relations of class 3 were left intact for both conditions (c.f. Wirth \& Chase, 2002). Table 3 (upper row) shows the composition of blocks and trials during reversal training.

A continuous reinforcement $(\mathrm{CRF})$ schedule was in effect during reversal training for the rich and lean conditions. That is, selecting B2 in the presence of $\mathrm{A} 1$, and B1 in the presence of A2 resulted in feedback on each trial in which this selection was made. Accuracy in the new relations had to be above $90 \%$ before advancing to the next condition.

Post-reversal tests. Test blocks identical to the initial testing for equivalence were reintroduced to assess the impact of the baseline reversal on equivalence relations. Sessions 
during this phase repeated the format of two (post-reversal) test blocks followed by one (reversed) baseline block, and this compound of two test blocks and one baseline block alternated between conditions.

Retention tests. Two weeks after the last post-reversal test, participants returned to the laboratory for retention tests that were identical to the initial and post-reversal tests. No baseline or reversed baseline blocks were presented.

Results

\section{Baseline Training}

Table 4 shows the number of baseline blocks needed to reach the $90 \%$ accuracy criterion in baseline responding for the rich and lean conditions for each participant. For five of six participants, the stimulus classes trained with the rich schedule required fewer blocks to criterion than the classes trained with the lean schedule. With no apparent differences in accuracy among stimulus classes $(1,2$, and 3$)$ or order of conditions for this or any subsequent analyses, from this point forward data are collapsed across stimulus classes and order of conditions.

\section{Tests of Stimulus Equivalence}

Figure 2 shows performance of all participants on all types of trials during the first two blocks of equivalence tests for each condition. Only the first two blocks of tests are presented because performance on equivalence tests improved with continued testing, as is commonly reported in the literature (Green \& Saunders, 1998), and thus averaging all the test blocks would obscure initial differences between conditions. Symmetry tests (BA and CB relations) were at or near $100 \%$ accuracy for four participants in both conditions. Transitivity and combined tests (AC and CA relations) had the lowest performance in general. For five of the six participants performance on the rich condition was better than on the lean condition for most transitive and 
combined relations. This finding is illustrated more clearly in Figure 3 where only the transitive and combined relations are presented. Only participant 788 had more accurate responding in transitivity and combined tests for the lean condition than the rich condition.

Table 5 shows mean response speeds during initial equivalence tests for symmetry, transitivity, and combined trials. Response speed was calculated as the time elapsing from the comparison stimuli appearing on the screen to the participant clicking one comparison and is reported in responses per second. When participants responded correctly, they did so faster in the rich condition than in the lean condition for 15 of the 18 of the comparisons, and all participants responded faster in symmetry trials than in transitivity and combined trials. When responding was less than $90 \%$ accurate, the speed of responding to incorrect trials was also calculated. During initial equivalence tests only participant 300 had enough incorrect trials to analyze for both rich and lean conditions. For this participant, correct responding was faster for the lean condition for two of three comparisons, but incorrect responding was faster for the rich condition for two of three comparisons.

\section{Reversal Training}

Table 6 shows the number of blocks needed to reach the $90 \%$ accuracy criterion for the reversed $\mathrm{AB}$ relations (selecting $\mathrm{B} 2$ in the presence of $\mathrm{A} 1$ and $\mathrm{B} 1$ in the presence of $\mathrm{A} 2$ ). There were no systematic differences across conditions in the number of trials needed to reach this criterion. Table 7 shows response speeds during reversal training. For correct trials, three participants $(311,788$, and 425$)$ responded faster in the rich condition than in the lean condition and the remaining three participants responded faster in the lean condition. Three participants (300, 425, and 788) had enough incorrect trials in both conditions to compare and two of them (300 and 788) had faster responding in the rich than in the lean condition for incorrect trials. 


\section{Post-reversal Tests}

After reversal training, equivalence tests examined symmetric, transitive, and combined responding for the recently altered stimulus classes. In addition to the difference between rich and lean conditions, distinctions will be made between the following variables throughout this section and the next: a) original versus reversed stimulus classes, where the former refers to classes formed during baseline training and the latter refers to classes formed after the $\mathrm{AB}$ reversal; and b) targeted versus control relations. Targeted relations are likely to be affected by the $\mathrm{AB}$ reversal (BA, $\mathrm{AC}$, and $\mathrm{CA}$ relations for classes 1 and 2) and control relations should not be affected by such reversal $(\mathrm{CB}$ relations for all classes and $\mathrm{BA}, \mathrm{AC}$, and $\mathrm{CA}$ relations for class 3) according to previous research on baseline relations reversals (e.g., Pilgrim \& Galizio, 1990, 1995; Wirth \& Chase, 2002).

Figure 4 shows responding during post-reversal tests for participants 184, 221, and 788 . For these three participants, responding was slightly more consistent with the reversed classes (i.e., less resistant to change) in the lean condition than in the rich condition. Specifically, responding in the rich condition was divided between the original and reversed stimulus classes for participant 221 whereas responding in the lean condition was almost completely consistent with the reversed classes. For participant, 184, responding in the rich condition also was divided between original and reversed stimulus classes, but during the lean condition her responding was highly consistent with the reversed classes for symmetry trials. There was no responding to the reversed classes in the rich condition for participant 788, whereas some of the responding in the lean condition was consistent with the reversed classes. Responding in control relations remained accurate in both conditions except for participant 221 who had some disruption in the control relations for both the rich and lean conditions. 
Figure 5 shows responding during post-reversal tests for participants 300,311 , and 425 , whose responding was not different for the rich and lean conditions. Performance of participants 311 and 425 was almost completely consistent with the reversed classes for both conditions. Performance of participant 300 was highly consistent with the original classes for both conditions. Responding to the control relations remained accurate in both conditions for these three participants.

Table 8 shows response speeds during the first two blocks of post-reversal tests. Correct responding was faster in the rich condition than in the lean condition for 13 of 18 comparisons. In addition, correct responding generally was faster during post-reversal tests than during initial tests. The differences in correct response speed across types of relations during post-reversal tests were less consistent than they were in initial testing: only participants 788 , 425, and 300 maintained the pattern whereby responding was faster in symmetry trials than in transitivity and combined trials. Three participants $(184,788$, and 300$)$ had enough incorrect trials under both conditions to analyze. For two of them (788 and 300), responding during incorrect trials was faster in the rich condition than in the lean condition for two of three comparisons. Participant 184 had faster incorrect-trial responding to the lean condition for two of three comparisons.

\section{Retention Tests}

Figure 6 shows performance during retention tests for participants 184, 221, and 788, whose responding was more resistant to change in the rich condition than in the lean condition. Specifically, participants 184 and 221 had no reversed-class responding in the rich condition and considerable responding to the reversed classes in the lean condition. Curiously, participant 184's responding in the C1B1 control relations indicated that these relations had reversed 
although these relations were not reversed by the experimental contingencies. Participant 788's responding was mainly consistent with the original classes in both conditions, but slightly more accurate in the rich than in the lean condition. Responding in control relations was highly accurate in both conditions for all participants but 184 .

Figure 7 shows performance during retention tests for participants 300,311 , and 425 , whose retention performance was not consistent with the expected results. Responding of participant 300 was highly consistent with the original classes for both conditions; responding of participant 425 was highly consistent with the reversed classes for both conditions; and responding of participant 311 was consistent with the reversed classes for the rich condition and mainly consistent with the original classes for the lean condition. Performance on control relations was highly accurate for all participants.

Table 9 shows response speeds during retention tests. Responding was faster in the rich condition than in the lean condition in 10 of the 18 comparisons, and responding to symmetry trials was generally faster than responding to transitivity trials (response speed was similar for symmetry and combined equivalence trials). Only participant 425 had enough incorrect trials in both conditions to analyze and there were no important differences in her incorrect responding to the rich and lean conditions.

\section{Discussion}

The present experiment examined whether manipulating the rate of reinforcement affected resistance to change of behavior under conditional stimulus control. To that aim, baseline training on stimulus relations was conducted using rich and lean schedules of reinforcement. Training was followed by equivalence tests, reversal of $\mathrm{AB}$ relations, postreversal equivalence tests, and retention tests. 
Baseline training. The rich reinforcement condition resulted in faster acquisition of the criterion performance of $\mathrm{AB}$ relations than the lean reinforcement condition, replicating similar results obtained by Dube and McIlvane (2002). Acquisition of baseline relations was faster for $\mathrm{AB}$ relations than for $\mathrm{BC}$ relations regardless of reinforcement rate. This finding is also consistent with previous literature suggesting that training baseline relations in successive phases results in faster acquisition for the later phases when compared to the early phases as the participants gain experience with the task (Harrison \& Green, 1990).

Tests of stimulus equivalence. Manipulating reinforcement rate during training resulted in initial test performance that was better in the rich condition than in the lean condition for five of six participants. These differences in initial test performance are noteworthy because the baseline relations were trained to the same accuracy criteria for both the rich and lean conditions before introducing equivalence tests. According to Sidman (2000), untrained equivalence relations emerge from the trained relations. In the present experiment, the trained relations upon which equivalence is based were mastered at the same level for both conditions before introducing the equivalence tests, and therefore differences in tests cannot be attributed to differences in the mastery of baseline relations.

The length of continued baseline training after the accuracy criterion was reached, however, differed across conditions. Baseline relations in the rich condition were mastered sooner than those in the lean condition, yet participants continued training in the rich condition until both conditions met the accuracy standard. Thus, baseline relations in the rich condition were overtrained. Because overtraining has been associated with improved application, a form of untrained responding (Brown, 1970), it is possible that overtraining of the rich condition in the 
present experiment accounted for the higher performance on the equivalence tests for that condition.

Reversal training. Most participants' behavior adapted rapidly to the reversed baseline discriminations in both conditions, contrarily to Dube and McIlvane (2002)'s finding that participants made more errors in the rich condition than in the lean condition when contingencies reversed. One possible reason for the discrepancy between the results of this experiment and those of Dube and McIlvane is the difference in populations - typically developing college students in the current study and participants with developmental delays in Dube and McIlvane's study. The swift change to reversed baseline relations is consistent with the rapid reversal in baseline relations found by Pilgrim and Galizio (1995) and Pilgrim, Chambers, and Galizio (1995) for typically-developing participants, suggesting that responding of these population may be highly sensitive to baseline reversals regardless of the reinforcement rate used during baseline training.

Post-reversal tests. For three of six participants, relations adapted to the reversal more readily for the lean condition than for the rich condition, consistently with the behavioral momentum prediction. There were no differences in the resistance to change, though, for the other participants.

The lack of a systematic effect of reinforcement rate following baseline reversals across participants may be due to the two possible patterns of responding after the reversal. After reversing $\mathrm{AB}$ relations, the new BA symmetry relations are unambiguous (B1A2 and $\mathrm{B} 2 \mathrm{~A} 1)$. When $\mathrm{CA}$ and $\mathrm{AC}$ trials are presented, however, there are two logical outcomes. First, participants may select $\mathrm{C} 1$ in the presence of $\mathrm{A} 1$ and $\mathrm{C} 2$ in the presence of $\mathrm{A} 2$ (and similarly select $\mathrm{A} 1$ in the presence of $\mathrm{C} 1$ and $\mathrm{A} 2$ in the presence of $\mathrm{C} 2$ ). This pattern of behavior described 
as partial reversal (Garotti, de Souza, de Rose, Molina, \& Gil, 2000) would indicate that symmetry relations were altered by the reversal of $\mathrm{AB}$ relations, but transitive and combined relations were not. The other possible outcome consists of selecting $\mathrm{C} 2$ in the presence of A1 and $\mathrm{C} 1$ in the presence of $\mathrm{A} 2$ (and similarly $\mathrm{A} 2$ in the presence of $\mathrm{C} 1$ and $\mathrm{A} 1$ in the presence of $\mathrm{C} 2$ ). Such pattern of behavior described as complete reversal would suggest a reorganization of the stimulus classes where the $\mathrm{AB}$ reversal altered the symmetry relations and also the transitive and combined relations (cf. Pilgrim \& Galizio, 1990, 1995).

In the present experiment, complete reversals were more frequent than partial reversals. Participants 184, 221, and 788, however, had some degree of partial reversals, with their responding distributed across the original and reversed classes for the different types of relations. This is noteworthy because these participants' behavior during post-reversal tests was consistent with the behavioral momentum prediction. Sensitivity to differences in reinforcement rate, then, may be related to the presence of partial reversals, a point that will be addressed in detail below.

Retention tests. Following the behavioral momentum metaphor, responding that is resistant to changes in contingencies should be also resistant to the "debilitating" effects of the passage of time without practice. Furthermore, it has been asserted that retention is affected by environmental manipulations in a similar way as endurance, resistance to distraction, and other manifestations of resistance to change are (Binder, 1996; Dougherty \& Johnston, 1996; Walker, 2005).

For three participants, the original classes were better retained for the rich condition than for the lean condition as predicted by the behavioral momentum theory, but retention did not differ across conditions for the remaining participants. Despite these inconsistent results across participants, there was an orderly relation between resistance to change during reversal and 
resistance to change after the retention period within participants. Participants whose richcondition responding was more resistant to change than lean-condition responding during the reversal also had rich-condition responding that was more persistent than lean-condition responding after the retention interval. This relation suggests that resistance to change was consistently affected by reinforcement rate in those cases.

Response speeds. Responding during initial tests was typically faster in the rich condition than in the lean condition, replicating the faster responding associated with richer reinforcement schedules (e.g., Belfiore et al., 1997; Fath, Fields, Malott, \& Grossett, 1983; Mace et al., 1988). This pattern was maintained during post-reversal tests except for participants 184 and 221 whose responding was faster and also more accurate in the lean than in the rich condition. Thus, accuracy and response speed in general were associated across conditions and participants, as expected from the finding that response speeds are consistent with accuracy but more sensitive to differences in conditions than accuracy (Spencer \& Chase, 1996). During retention tests, differences in response speeds for the rich and lean conditions were smaller than during previous tests, and the initial speed differences in symmetry, transitivity, and combined trials decreased, as expected when tests have been administered repeatedly (Fields, Landon-Jimenez, Buffington, \& Adams, 1995).

Conclusions. The manipulation of reinforcement rate had a small consistent effect on the emergence of stimulus equivalence responding consistently with the behavioral momentum theory. After initial tests for equivalence, however, reinforcement rate continued to have an effect consistent with behavioral momentum for only some participants. One limitation of this experiment was the overtraining of the rich condition, a variable that may have interacted with reinforcement rate in unforeseen ways. Fitzgerald (2001) found that overtraining baseline 
relations did not affect performance on subsequent stimulus equivalence tests. In Fitzgerald's experiment, however, the overtraining condition did not involve an accuracy criterion as it did in the present experiment, and thus the possible effects of overtraining in the present experiment remained an issue because of the facilitative role of overtraining on performance (Driskell, Willis, \& Cooper, 1992).

Experiment 2 sought to replicate Experiment 1 while controlling for overtraining across the rich and lean reinforcement rate conditions. The commonly-used definition of overtraining was applied in which a pre-established accuracy criterion is used to determine overtraining (cf. Driskell et al., 1992). Controlling for overtraining also had the purpose of more precisely examining the possible effects of reinforcement rate on resistance to change during $\mathrm{AB}$ reversal and retention while discarding the possibility that overtraining may have affected responding in those experimental conditions in Experiment 1.

\section{EXPERIMENT 2}

Method

\section{Participants}

Six undergraduate female students (ages 18 to 22) completed the experiment. The recruitment procedure, incentives for participation, and selection criteria were the same as in Experiment 1.

\section{Apparatus and Setting}

The apparatus and setting were the same as in Experiment 1. The stimuli used also were the same as in Experiment 1 (shown in Figure 1). 


\section{Procedure}

This experiment followed the same design as Experiment 1, with the only modification of controlling the number of blocks experienced after mastery on each condition (see details below).

Before the first experimental session, participants were randomly assigned to the relative or absolute condition for overtraining. Overtraining studies either use a pre-specified number of overtraining sessions or they arrange for training to take place and then provide overtraining sessions that exceed the number of training sessions by a pre-specified percentage such as $50 \%$ or $100 \%$ overtraining (e.g., Driskell et al., 1992). Without a clear cut recommendation for which criteria to use in studies in which two or more conditions are matched for overtraining, the present experiment arranged for both the absolute and relative criteria for overtraining while controlling for overtraining across rate conditions.

In the absolute condition, the number of blocks that one rate condition had in excess of those needed to reach the mastery criterion was added to the other rate condition. For example, if one condition took four blocks to reach $90 \%$ accuracy and the other condition took six, then the first condition had received two blocks of overtraining. Thus, to yoke the absolute number of overtraining blocks, the condition that took six blocks to master then received two additional blocks of training, and the first condition received no additional blocks.

In the relative condition, the percentage of overtraining that one rate condition had relative to itself was yoked to the other condition. For example, if one condition took four blocks to reach $90 \%$ accuracy and the other condition took six, then the first condition had received $50 \%$ overtraining (the two overtraining blocks is $50 \%$ of four blocks). To yoke the percentage of overtraining across conditions, the condition that took six blocks to master received three 
additional blocks of training (three blocks is $50 \%$ of six blocks), and the first condition received no additional blocks.

Apart from the overtraining arrangements, the schedules of reinforcement, structure of trials within blocks, and order of training ( $\mathrm{AB} \rightarrow \mathrm{BC} \rightarrow$ combined training) were the same as in Experiment 1, and so were the remaining experimental phases. Tests of stimulus equivalence were introduced after participants were responding with a $90 \%$ level of accuracy to the baseline relations. These tests were followed by reversal training in which the $\mathrm{AB}$ relations for classes 1 and 2 were reversed in both the rich and lean conditions. Post-reversal tests followed reversal training to assess the resistance to change of emergent responding. Finally, retention tests were administered two weeks after the last post-reversal test to assess maintenance of stimulus classes.

Results

\section{Baseline Training}

Table 10 shows the number of blocks that each participant needed to reach the $90 \%$ correct criterion in each condition. In $\mathrm{AB}$ training, two participants needed more blocks to master the accuracy criterion in the lean condition than in the rich condition and the others needed the same number of blocks on both conditions. The number of blocks needed to master the BC baseline relations varied unsystematically across conditions.

Table 11 shows the amount of overtraining to which each participant was exposed. Participants 522, 633, and 854 were assigned to the relative criterion for overtraining. Participant 522 received $25 \%$ overtraining during $\mathrm{AB}$ training and $100 \%$ overtraining during $\mathrm{BC}$ training. Participants 633 and 854 did not receive overtraining in either $\mathrm{AB}$ or $\mathrm{BC}$ training because they reached the 90\% accuracy criterion within the same number of blocks in the rich and lean conditions. Participants 147, 556, and 987 were assigned to the absolute criterion for 
overtraining. Participants 147 and 987 did not need overtraining for AB or BC training, but did for combined training; participant 556 received three blocks of overtraining for AB relations and one block for BC relations.

\section{Tests of Stimulus Equivalence}

Figure 8 shows accuracy levels during initial equivalence tests. Performance did not differ systematically across conditions for three of six participants. Performance for the other three participants $(522,663$ and 854$)$ was better on the lean condition than on the rich condition.

Table 12 shows response speeds during initial tests. In general, correct responding was faster in the lean condition than in the rich condition and faster for symmetry trials than for transitivity and combined trials. For participants who had enough incorrect trials to allow comparing incorrect responding across conditions (147 and 987), there were no systematic differences in incorrect response speed across conditions.

\section{Reversal Training}

Table 13 shows the number of blocks needed to meet the $90 \%$ accuracy criterion during reversal training. Participants 522 and 556 needed two blocks to meet the criterion in the rich condition and one block in the lean condition. The remaining participants needed the same number of blocks to meet the reversal criterion for both conditions.

Table 14 shows response speeds for each condition during the first two blocks of reversal training. Four of six participants $(147,522,633$, and 854) had faster correct responding in the lean condition than in the rich condition. Two participants (633 and 854) had enough incorrect responding in both conditions to allow comparisons, and both had faster incorrect responding in the lean condition than in the rich condition. 


\section{Post-reversal Tests}

Figure 9 shows responding during post-reversal tests for participants 522, 556, 854, and 987, who had a similar pattern of behavior during this condition. All these participants' responding was more consistent with the original classes for the rich condition than for the lean condition, and more consistent with the reversed classes for the lean condition than for the rich condition. Responding to the control relations remained at high levels of accuracy for participant 556. Participants 522 and 854 had lower accuracy levels in the control relations for the rich condition than for the lean condition, but this was a continuation of their previous performance because they also had low performance on these relations during initial equivalence tests. Participant 987 responded to the CB control relations of classes 1 and 2 of both conditions as if those relations had been reversed, although no such reversal was arranged in the experiment.

Figure 10 shows responding during post-reversal tests for participants 147 and 633. Participant 147's responding changed immediately to the reversed relations for both conditions. Participant 633's responding was 50\% consistent with the original classes and 50\% consistent with the reversed classes. Responding to the control relations remained highly accurate for these two participants.

Table 15 shows response speeds during post-reversal tests. For correct trials, three participants responded faster in the rich condition than in the lean condition; the other three participants' response speeds varied unsystematically across conditions. Symmetry trials were responded to faster than transitivity trials, and there was little difference between the response speeds for symmetry and combined trials. Three participants (556, 633, and 987) had enough incorrect responding to allow comparing across conditions. Only participant 556 had incorrect 
responding that was faster in the rich condition; the other two participants responded faster under the lean condition.

\section{Retention Tests}

Figure 11 shows responding during retention tests for participants 522 and 854. For these participants, responding was slightly more consistent with the original classes in the rich condition than in the lean condition. Their performance on control relations for the rich condition was relatively low compared to the corresponding relations in the lean condition. This, however, is the same pattern that these participants had during initial and post-reversal tests.

Figure 12 shows responding during retention tests for participants 556 and 633. Their performance on the targeted relations was completely consistent with the original classes for both the rich and lean conditions, and their performance on the control relations was highly accurate for both conditions.

Figure 13 shows retention test performance for participants 147 and 987 . These participants' performance was slightly more consistent with the reversed classes for the rich condition than for the lean condition, indicating that lean-condition responding was more resistant to change. Furthermore, they responded to some of the control relations as if those relations had been reversed, although no such reversal was arranged in the experiment.

Table 16 shows response speeds during retention tests for all participants. When considering correct trials, two participants responded faster in the lean condition than in the rich condition, and the remaining participants' response speeds did not differ systematically across conditions. For most participants, responding was faster in symmetry trials than in transitivity trials, with little differences between the response speeds of symmetry and combined trials. Two 
participants (522 and 854) had enough incorrect responding to warrant a comparison of incorrect trials across conditions. Both of them had faster responding in the lean than in the rich condition.

\section{Discussion}

This experiment was a systematic replication of Experiment 1 with the amount of overtraining constant across the rich and lean reinforcement rate conditions. The main purpose was to determine whether the better performance on initial equivalence tests of the rich condition found in Experiment 1 was the product of baseline overtraining. A secondary purpose of the present experiment was to determine whether removing overtraining may change the effect of rich and lean conditions on post-reversal and retention tests.

Tests of stimulus equivalence. Performance on initial tests varied across conditions, with some participants having better rich-condition performance and some having better leancondition performance. These results are different from those found in Experiment 1, where performance on initial equivalence tests was better for the rich condition. Because overtraining was kept constant across conditions in the current experiment and the initial difference in equivalence test performance disappeared, it appears that the results of Experiment 1 may be attributed to overtraining in the rich condition. Dube and McIlvane (1996) suggested that emergence of equivalence relations may be a product of both reinforcement rate and overtraining, and the results from this experiment seem to support that claim. Reinforcement rate by itself did not have differential effects on the emergence of equivalence relations when overtraining was not given, at least for the reinforcement rate parameters used here.

It must be noted that overtraining occurred only rarely in this experiment: most participants needed few blocks to master each set of baseline relations, and therefore the need to control for overtraining was minimal. The little overtraining that occurred also prevents any 
conclusions about possible differential effects of relative versus absolute criteria for overtraining. Only three participants were assigned to each overtraining criterion, and there were no differences between overtraining criteria in terms of participants' performance in initial, postreversal, or retention tests.

Reversal training. Two participants made considerably more errors in the rich condition than in the lean condition when the $\mathrm{AB}$ relations were reversed. Thus, the reinforcement rate had the expected effect of strengthening the stimulus control exerted by the original stimulus relations for more participants. This result represented an improvement upon the results obtained in Experiment 1, but the greater resistance to change of the rich condition still was not consistent across participants.

Post-reversal tests. Responding during post-reversal tests was consistent with the predictions of behavioral momentum for four of six participants. Furthermore, all the participants whose responding was consistent with behavioral momentum had partial reversals in one or both conditions, whereas the two participants whose responding was inconsistent with behavioral momentum had complete class reversals. This pattern is similar to that of Experiment 1 and points to the possibility that classes that reverse partially are more sensitive to the effects of reinforcement rate than classes that reverse completely. This finding will be discussed further in the general discussion.

That four participants responded consistently with behavioral momentum represented an improvement over Experiment 1 in terms of controlling the effects of reinforcement rate across participants. A possible explanation for the increase in reversals relative to Experiment 1, however, is that in Experiment 2 participants received less baseline training than in Experiment 1. Garotti et al. (2000) suggested that short baselines before reversal training may result in 
reversed classes that override the original classes. Although we are not aware of any studies confirming or disconfirming this prediction, it is consistent with Dube and McIlvane (1996)'s assertion that with continued exposure to the equivalence tasks, participants' responding becomes more consistent with the properties of equivalence relations. Thus, the fact that participants in Experiment 2 received relatively little training in the original relations before advancing to reversal training may have resulted in the original equivalence classes still being formed when the reversal was introduced. Behavior in transition is more sensitive to changes in the contingencies than behavior that is established (Doughty et al., 2005; Joyce \& Chase, 1990), and so the baseline reversal in this experiment may have been implemented on behavior that was more sensitive to it than in Experiment 1.

Finally, the possibility that differences between Experiments 1 and 2 were due to individual differences in the participants cannot be ruled out. It is possible that participants in Experiment 2 had special characteristics that made them more likely to need less training in the baseline relations, more likely to have partial reversals, and more likely to be affected by the reinforcement rate manipulation.

Retention tests. Only two of six participants (556 and 633) responded exclusively to the original classes, whereas the remaining four participants had some responding to the reversed classes in both conditions. This retention of reversed classes contrasts with the predominant retention of original classes found in Experiment 1 and by Wirth and Chase (2002). This result may be attributed again to the length of baseline training: in this experiment, participants needed relatively few blocks to master the baseline relations and thus they received short training on these relations. The number of blocks needed to master the reversed relations was similar to the number of blocks needed to master the baseline relations for many participants, resulting in 
comparable amount of training for the original and reversed classes and facilitating greater retention of the reversed classes than that of Experiment 1.

Of the four participants who responded to reversed classes, two (522 and 854) did so more for the lean condition than for the rich condition, a result consistent with the behavioral momentum prediction. The other two participants (147 and 987) had more responding to the reversed classes for the rich condition. Participants 147 and 987, however, responded to some control relations in both conditions as if those relations had been reversed. The baseline reversals may have disrupted relations to which the reversal was not applicable, and thus it is difficult to evaluate the connection between the reversal of control relations and the lack of effect of the rate of reinforcement manipulation during retention. For participant 987, this incorrect reversal of control relations during retention tests was a continuation of the pattern shown during postreversal tests. For participant 147, the incorrect reversal of control relations did not occur during post-reversal tests but began during retention tests. Her retention of some lean-condition relations was at $0 \%$ (i.e. not consistent with either original or reversed classes). It could be said that her performance during post-reversal tests was maintained by the prevailing contingencies of the reversal training embedded in that phase, but after two weeks and no feedback for retention tests her performance on the lean condition deteriorated.

Response speeds. There were no systematic differences in response speed between the rich and lean conditions during initial tests. In Experiment 1, the rich condition yielded faster responding during initial tests, but this difference was absent when overtraining was controlled in Experiment 2. As was the case for accuracy, then, overtraining may be necessary for response speeds to be differentially sensitive to the reinforcement rate manipulation. In addition, during initial equivalence tests, responding was fastest in symmetry trials, followed by combined trials, 
and slowest for transitivity trials. This pattern is consistent with that of Experiment 1 and it replicates the findings of Spencer and Chase (1996). During post-reversal tests, three of the participants who responded consistently with behavioral momentum had faster responding in the lean condition than in the rich condition, replicating the relation between accuracy and response speed observed in Experiment 1.

Conclusions. When overtraining was no longer in effect for the rich condition, participants' responding on initial equivalence tests was equal across conditions. This preliminary evidence suggests that, as pointed out by Dube and McIlvane (1996), differences in equivalence emergence may be a product of rate of reinforcement and length of training. As in Experiment 1, there was high variability across participants regarding the effects of the reinforcement rate manipulation. Although more participants' behavior was consistent with the behavioral momentum prediction than in Experiment 1, the effects were not uniform.

The lack of robust between-participant effects may have been due to the simplicity of the task. Participants had perfect or near-perfect performance on baseline relations by the end of the initial equivalence tests, and such a ceiling effect may have obscured the potential effects of reinforcement rate.

A second limitation concerns the logical possibility of either partial or complete class reversals following baseline reversals. Consistency with partial or complete class reversals could not be manipulated in this experiment, and this resulted in uncontrolled variability of behavior across participants. The existence of partial and complete reversals as two logical outcomes possibly jeopardized the reliability of baseline reversals as a behavioral disruptor and suggests that other disruptors be used. 
A third possible reason for the lack of consistent results after the reversals concerns stimulus control of responding to the rich schedule versus the lean schedule. Nevin (1988) suggested that reinforcement rate may affect resistance to change because the stimuli correlated with the richer schedule of reinforcement are more discriminative for reinforcement than the stimuli correlated with the leaner schedule. In this experiment, the visual properties of the stimuli may not have facilitated discrimination across conditions, particularly during unreinforced test trials. It is not possible to conclude whether participants in this experiment were able to discriminate the stimuli associated with each condition, but the fact that all the stimuli were geometric characters may have made such discrimination a difficult one, and generalization could have neutralized possible differences.

Experiment 3 was designed to address some of the limitations of Experiments 1 and 2 and to maximize the differences between the rich and lean schedules. First, the stimulus classes were augmented to five members per class to make the experimental task more difficult and to prevent ceiling effects on accuracy. Second, a distraction task was substituted for the baseline reversal as the behavioral disruptor. Wilkie, Summers, and Spetch (1981, Experiment 1) found that interpolating distracting stimuli between the sample and comparisons resulted in decreased accuracy on a delayed matching-to-sample procedure. Presenting extraneous sources of stimulation also has been used as a test of resistance to change, with the common finding that behavior maintained by rich reinforcement rates is less disrupted by the distractor than behavior maintained by lean reinforcement rates (e.g., Mace et al., 1990). It was expected that this disruptor would provide a measure of resistance to change without the limitations of baseline reversals. The third modification consisted of making the classes of stimuli associated with the rich and lean conditions more discriminable by having one set of geometric figures as stimuli 
and another set of Chinese characters. Finally, the schedules were changed to continuous reinforcement for the rich condition and variable-ratio 4 (VR 4) for the lean condition to ensure adequate response acquisition with the new larger classes.

\section{EXPERIMENT 3}

\section{Method}

\section{Participants}

Six female undergraduate students (ages 18 to 20) began this experiment. Two participants failed to perform above chance levels in the equivalence tests and one participant withdrew from the experiment shortly after beginning equivalence tests. Their data were excluded from analysis. Recruitment, incentives for participation, and selection criteria were identical to Experiments 1 and 2, with the added requirement that participants were are not familiar with Chinese, Korean, or Japanese because Chinese characters were used as stimuli. Apparatus and Setting

The apparatus and setting were the same as in Experiments 1 and 2. Design

Table 17 shows the basic design of the experiment, and details for each condition are presented below. As in Experiments 1 and 2, the design consisted of establishing two baselines of stimulus classes maintained at different reinforcement rates, testing for equivalence relations, and introducing a disruptor to compare resistance to change. 


\section{Procedure}

Stimuli. The stimuli were arranged in two sets of three stimulus classes (set I and set II), with each class consisting of five stimuli. Figure 14 shows the stimuli within each class and set for this experiment.

Baseline training. Participants were presented with the same instructions as in Experiments 1 and 2 at the beginning of the study. Following instructions, a simultaneous matching-to-sample procedure was used to train participants in the baseline relations. The differences in baseline training with respect to Experiments 1 and 2 were: first, the schedules in operation were continuous reinforcement $(\mathrm{CRF})$ for the rich condition and VR 4 for the lean condition. In the lean condition, the VR 4 schedule arranged for feedback to be presented after an average of four responses, based on the accuracy of the last response as before. Second, because in the present experiment classes had five instead of three members, baseline training was more extended than in Experiments 1 and 2. Table 18 (top) shows the structure of training sessions for each stage of baseline training.

Classes were trained linearly $(\mathrm{A} \rightarrow \mathrm{B} \rightarrow \mathrm{C} \rightarrow \mathrm{D} \rightarrow \mathrm{E})$ beginning with $\mathrm{AB}$ relations. During the $\mathrm{AB}$ stage of training, participants were trained on the A1B1, A2B2, and A3B3 relations for each condition. After performance on $\mathrm{AB}$ relations was at least $90 \%$ accurate, $\mathrm{BC}$ relations were trained with the same procedure used to train $\mathrm{AB}$ relations. Training for the $\mathrm{CD}$ and $\mathrm{DE}$ relations was introduced after participants responded with $90 \%$ accuracy to the previous relations.

Training was organized in blocks of 36,54 or 72 trials, depending on the training stage, and cumulative training was in effect throughout baseline training (that is, each time a new relation was introduced, training trials for the previously trained relations were presented within the same block). Two stages of DE training (DE1 and DE2) were provided to equate the number 
of DE trials to that of other trials while keeping the block composition at a maximum of 72 trials throughout training. During final training, all relations were presented equally often. By the end of baseline training, participants had been exposed to the same number of trials across the AB, $\mathrm{BC}, \mathrm{CD}$, and $\mathrm{DE}$ relations.

Tests of stimulus equivalence. After responding reached the $90 \%$ accuracy criterion for the final training stage, blocks of test trials assessing the emergence of symmetry, transitivity, and combined equivalence relations were introduced. During this stage, two blocks of tests for each condition were presented at the beginning of the session, followed by one block of baseline training for each condition. Baseline blocks had the same composition and schedule of reinforcement as the last block of the baseline training phase. Test blocks consisted of 48 trials, of which 12 trials assessed symmetry relations and 18 trials assessed each of the transitivity and combined equivalence relations. Table 18 (bottom) shows the composition of a test block. No performance feedback was given during test blocks. The accuracy and stability criteria required to advance to the next stage were identical to those of Experiments 1 and 2.

Disruption. Disruption sessions were run for training and test blocks. During disrupted training sessions, a delayed matching-to-sample procedure was in effect instead of the simultaneous MTS procedure used for training. The delayed MTS procedure imposed a temporal delay between the offset of the sample and the onset of the comparisons. During that interval, a distraction task was presented and participants had to complete it before being able to see and select the comparisons. The distraction task consisted of a grid of extraneous stimuli presented on the screen (stimuli shown in Figure 15). The distraction stimuli were presented five times in random order and in random positions within the grid. Each time a distraction stimulus appeared, the participant had to click on it to make it disappear and make the next distraction stimulus 
appear. Clicking on the fifth distraction stimulus resulted in the onset of the comparisons, and the participant was now able to select a comparison. Thus, the delay between the offset of the sample and the onset of the comparisons depended on the time that participants took to respond to the distraction task. Feedback was provided according to the schedule in operation for that condition -i.e., a CRF or a VR 4 schedule of reinforcement.

Disruption during testing was identical to that of training, except no performance feedback was provided for any trial.

Retention tests. One retention session was conducted two weeks after the last disruption session. A retention session presented test blocks only for the rich and lean conditions. No feedback was provided.

Results

\section{Baseline training}

Table 19 shows the number of blocks needed by each participant to meet the performance criterion for the baseline relations. In general, participants needed more blocks to meet criterion in the lean condition than in the rich condition, particularly during training of the $\mathrm{AB}$ relations. Table 20 shows response speeds during the last block of baseline training. For participant 506, responding was faster during the rich condition than during the lean condition. Responding of participants 378 and 458 was faster in the lean than in the rich condition.

\section{Tests of stimulus equivalence}

Figure 16 shows accuracy performance for the first two blocks of equivalence tests. Participant 506's test performance was higher in the rich condition than in the lean condition. Participants 378 and 458's performance was higher in the lean condition than in the rich condition, and their performance in the rich condition was low (17\% to $67 \%$ correct) for all 
relations except symmetry. Performance is presented for each type of relation (symmetry, transitivity, and combined) and transitivity and combined relations are further divided into onenode, two-node, and three-node relations because of the differences in performance typically found as a function of nodal distance (Fields et al., 1990; 1995). Nodal distance refers to the number of stimuli that separate two potentially related stimuli. For example, AC relations are separated by $\mathrm{B}$ as one node, because of the training sequence $\mathrm{A} \rightarrow \mathrm{B} \rightarrow \mathrm{C}$; $\mathrm{AD}$ relations are separated by two nodes (B and C); and AE relations are separated by three nodes (B, C, and D). Only the responding of participant 458 differed systematically across nodal distances.

Table 21 shows response speeds for each condition for each nodal distance during the first two blocks of equivalence tests. Participant 506's responding was faster in the rich condition than in the lean condition. For participants 378 and 458, responding was faster in the lean than in the rich condition. Only participant 458 had enough incorrect responding to compare incorrect response speed, and her responding was faster for the lean condition even for incorrect responses. For all participants, responding was faster in symmetry trials than in trials where stimuli where separated by one or more nodes, but did not differ systematically across the number of nodes separating the stimuli.

\section{Disruption}

The disruption procedure was introduced for both training and testing blocks. Table 22 shows accuracy levels during the last block of regular training and the first block of training disruption. Accuracy decreased in the rich condition for two participants and increased in the lean condition for two participants when the disruptor was introduced.

Table 23 shows response speeds during the last block of baseline training and the first block of disruption training, and Figure 17 shows the same data expressed as a proportion of 
baseline. Smaller proportions of baseline indicate slower responding relative to baseline, greater disruption, and less resistance to change. Participant 378's responding became faster during the disruption phase than during baseline, whereas participants 458 and 506's responding became slower. Proportion of baseline response speeds were faster in the rich condition than in the lean condition for two participants (378 and 506).

Figure 18 shows accuracy levels during the first block of testing disruption as a proportion of performance during the last block of initial testing. Accuracy in some relations increased with the disruptor (in the rich condition for participant 378 and in the lean condition for participant 506). Only participant 378 's responding was generally lower in the lean condition than in the rich condition.

Retention tests. Figure 19 shows accuracy of performance during retention tests for the three participants. Retention test performance showed no consistent effect of schedule, with participant 378 showing better retention under the lean condition, participant 506 showing better retention under the rich condition, and participant 458 showing equal performance under the two conditions. Table 24 shows response speeds during retention tests. Responding was faster in the lean condition than in the rich condition for all participants.

\section{Discussion}

Experiment 3 attempted to assess resistance to change of responding under conditions designed to maximize sensitivity to differences in reinforcement rate. Five-member stimulus classes were used to increase task difficulty, a different disruptor was used that was more consistent with disruptors used in other studies, and stimuli correlated with the rich schedule were selected that were likely to be discriminated from those correlated with the lean schedule. 
Despite these attempts to improve the experimental test of rate of reinforcement on the accuracy of complex human behavior, Experiment 3 was largely unsuccessful.

As in Experiments 1 and 2, participants required fewer blocks of trials to master the baseline relations in the rich condition than in the lean condition. During equivalence tests, however, two participants' responding was more accurate and faster in the lean than in the rich condition. Although the disruption procedure affected the response speeds of training trials, it did not affect test trials and had inconsistent effects on performance accuracy. Finally, the effects of rate of reinforcement on retention performance were inconsistent across participants.

Before discussing these inconsistencies, it must be noted that of the five participants who began the experiment, only three demonstrated equivalence relations, and one of those three needed extensive testing before performance on test trials met the criteria for equivalence. The frequent failure to obtain equivalence responding must qualify any conclusions drawn from this experiment because it increases the likelihood that participants who showed emergent equivalence were different from the rest in unmeasured ways.

Having to respond to distraction stimuli during the sample-comparison interval did not have consistent affects in this study. This result is at odds with studies that have applied similar distraction procedures to behavior maintained by different reinforcement rates (e.g., Dube \& Mcllvane, 2001; Mace et al., 1990). The selective effect of the disruptor on the speed of responding to training trials and not testing may be related to the disruptor being introduced for training trials before it was introduced for test trials, and thus participants had experience with the disruption procedure by the time they responded to the test trials.

The lack of changes in accuracy as a result of the disruptor also stands in contrast with the findings of Wilkie et al. (1981). In their experiment, adding visual stimuli during the delay 
between the sample and comparisons decreased accuracy in the matching-to-sample task. It must be noted that as baseline accuracy improved, accuracy during disruption also improved in Wilkie et al. Thus, the extent to which accuracy was disrupted in Wilkie et al. may have been a function of initial low levels of baseline accuracy; their results may not be comparable to responding that has reached high accuracy and speed levels like in the current study (cf. Johnson \& Layng, 1992).

Further support for the problem of disrupting highly accurate and fluent baseline performance comes from the lack of systematic disruption of responding during distraction also was found by Walker (2005). In addition, the only baseline performance that was disrupted in the current experiment (the rich condition for participant 378) was also the performance with the slowest responding before the disruptor was introduced. That accuracy during disruption deteriorated more in test blocks than in the highly-accurate training blocks also supports this interpretation. In the present study, it is likely that the disruptor was imposed upon responding that was at high strength regardless of the rate of reinforcement used, and thus responding was not disrupted.

Although retention performance was inconsistent across participants, it was consistent with other measures of resistance to change within the study. For example, participant 506's responding during initial tests, disruption, and retention was more accurate (and also faster) in the rich condition than in the lean condition. For participant 458, responding during disruption and retention was more accurate for the rich condition, too. Conversely, participant 378's responding was more accurate and faster in the lean condition than in the rich condition in almost all experimental stages. The consistency of patterns of responding during initial tests of equivalence, under the disruptor, and on the retention test within each participant suggests that 
response strength was related to the rate of reinforcement used. Why the relation was contrary to that expected for some participants and not others is not readily explainable because the present data do not allow determining whether behavior was a product of the specific schedule-stimuli relation arranged in the experiment or whether other participant variables were at play.

Conclusions. The changes made in Experiment 3 did not result in systematic differences in resistance to change across conditions that were consistent with behavioral momentum. Firm conclusions about the effectiveness (or lack thereof) of augmenting the discriminability of conditions cannot be drawn from this experiment. First, although the stimuli correlated with one reinforcement rate were made more distinct from stimuli correlated with the other reinforcement rate, the size of the stimulus classes was also increased. It was then not possible to assess the effectiveness of increasing the condition discriminability because this change was accompanied by an increase in task difficulty. Second, it is possible that the selection of these particular stimuli (abstract geometric figures versus Chinese characters) affected responding in unforeseen ways.

Additionally, experience with the task obscured potential differences in response speeds across conditions, a reason to suggest that future attempts introduce the disruptor only for testing blocks, instead of introducing it for both training and testing blocks. The distraction procedure also may have failed because of the short delay that it imposed between the sample and the comparisons. The delay depended on the speed of each participant going through the distraction stimuli, and that speed was usually fast, imposing a delay of only a few seconds. Future studies could use a distraction procedure that introduces a longer delay between sample and comparisons, preferably a delay controlled by the experimenter. Multiple distraction inputs also could produce greater behavior disruption. Although Wilkie et al. (1983) found that inputs in the 
same modality as the experimental task were more effective at disrupting behavior, other researchers have found that alternative sources of reinforcement disrupt behavior consistently (e.g., Mace et al., 1990; Podlesnik \& Chase, in press). Considering the high functioning level of college students, more potent (and probably multiple) distractors may be necessary in order to detriment accuracy of responding in discrete-trial tasks.

\section{General Discussion}

Nevin et al. (2003) and Dube and McIlvane (2002) suggested that responding reinforced on a rich schedule should not only maintain higher response rates during disruption than responding reinforced on a lean schedule; it also should maintain higher accuracy levels. That is, the concept of resistance to change should be applicable to response accuracy as well as to response rate.

The central purpose of the experiments reported here was to examine how the rate of reinforcement used to train baseline conditional discriminations affected resistance to change in accuracy of those baseline discriminations and of the equivalence relations based on them. One condition (rich) provided reinforcement after every correct response or after an average of two responses. The other condition (lean) provided reinforcement after an average of four or nine responses. Resistance to change under the rich and lean conditions was examined through different disruptors: baseline reversals, a distraction procedure, and a two-week period of no contact with the experimental contingencies. What follows summarizes the findings, discusses limitations, and suggests plans for future research. 


\section{Summary of findings}

Response acquisition. For all experiments, performance became accurate for the rich condition before it did so for the lean condition, consistently with findings in the area of response acquisition under different schedules of reinforcement (e.g., Dube \& McIlvane, 2002) and with the recommendation of providing frequent reinforcement when training equivalence classes (Green \& Saunders, 1998) as well as training in general. In this study, the lean condition was more "ambiguous" to participants because trials with no feedback did not provide an opportunity for learning the correct response. In the rich condition, learning proceeded relatively quickly because of the constant contact with the contingencies.

Equivalence emergence after overtraining in the rich condition. Dube and McIlvane (1996) hypothesized that the rate of emergence of stimulus equivalence during testing should be affected by the rate of reinforcement used during baseline training and by the amount of overtraining of baseline relations. The results obtained herein are consistent with their hypothesis: when a rich reinforcement rate was combined with overtraining in Experiment 1, emergence of equivalence performance was better for the rich condition. When overtraining in the rich condition was eliminated in Experiment 2, emergence of equivalence performance did not differ across conditions. In Experiment 3, only participant 506's performance was better for the rich condition than for the lean condition, and this participant also was the only one who received overtraining in the rich condition during all phases of baseline training. Thus, either overtraining or an interaction between overtraining and reinforcement rate may be necessary to strengthen responding in ways that affect equivalence test performance.

Partial class reversal after baseline reversal. As mentioned in the Discussion of Experiment 1, at least two outcomes are logically possible after baseline reversals, either partial 
reversal or complete reversal. Most participants responded in a manner that indicated complete reversal, but the participants whose responding indicated partial reversals were the only participants whose responding on the rich schedule was less disrupted than responding on the lean schedule.

When partial reversals occur, it is said that responding to equivalence relations is a set of dissociated properties (symmetry, transitivity, and combined symmetry and transitivity) rather than an integrated behavioral unit (cf. Pilgrim \& Galizio, 1990, 1995, 1996). Thus, responding characterized by partial reversals will be referred to as indicating poorly integrated classes. Responding characterized by complete reversals may be referred to as indicating integrated classes because changes in one set of relations are accompanied by changes in the rest of the relations. It is likely that poorly integrated classes were more susceptible to the reinforcement rate manipulation than integrated classes. That is, stimulus class responding that was "weaker" (i.e. less integrated) was more likely to be disrupted differentially depending on the rate of reinforcement used to maintain it.

Most of the participants who had poorly integrated stimulus classes responded to the reversed classes after the retention period. This is another indication that differences in the level of integration of equivalence classes predict how well the classes will be disrupted by changes in the environment. Spradlin et al. (1992) and Wirth and Chase (2002) noted that equivalence classes, once established, persist over extended periods of time. The partial reversals that occurred in the present study, however, suggest that the equivalence classes established by the original training were not integrated, and responding in turn was less likely to persist during the retention period. 
In summary, classes that are poorly integrated can be identified by the presence of partial reversals. These poorly integrated classes, in turn, were especially affected by baseline reversals and by the passage of time when the rate of reinforcement used to maintain them was lean.

It is still to be determined why some participants' responding demonstrated integrated stimulus classes and others' did not. It may be that the basis for the less integrated classes lies in participants' pre-experimental history; when participants came into the experiment, differences in reinforcement rate capitalized on deficits in class integration and facilitated differences across conditions. Alternatively, events in participants' pre-experimental history made their behavior more sensitive to differences in reinforcement rate, which in turn affected class integration. Determining the kinds of the histories that may have had these effects will require further experimentation.

\section{Limitations}

In the three experiments reported here, the effects of manipulating reinforcement rate were probably limited by the nature of the consequences used. Consequences consisted of positive and negative verbal messages displayed on the screen and positive messages were associated with the delivery of points redeemable for money. Both components of the positive feedback involve purported conditioned (as opposed to primary) reinforcers and function as reinforcers because of their assumed association with primary reinforcers in the participant's history (Galizio \& Buskist, 1988). Such reinforcers have come under increased scrutiny in studies of behavioral momentum.

Shahan and Podlesnik (2005) noted that the effects of reinforcement rate on the resistance to change of behavior maintained by conditioned reinforcement may not be the same as that maintained by primary reinforcers. Shahan and Podlesnik (Experiment 1) found that the 
observing responses in pigeons were not more resistant to prefeeding or extinction when they resulted in the display of the key light at high rates (rich condition) than when they resulted in the display of the key light at low rates (lean condition). The key lights were considered to be conditioned reinforcers for observing because they maintain observing and signaled the presentation of food (Squires \& Fantino, cited in Shahan \& Podlesnik, 2005). In Experiment 2, Shahan and Podlesnik again failed to find a behavioral momentum effect for observing behavior maintained by different rates of conditioned reinforcement, despite great differences in the ratios of rich to lean schedules (ratios of 6:1). In fact, the observing responses had greater resistance to change in the lean condition than in the rich condition for the majority of subjects.

Shahan and Podlesnik attributed the failure to obtain behavioral momentum effects with conditioned reinforcement to the "double" conditioning that must take place in such preparation. Resistance to change is determined mainly by relations between the stimuli and reinforcement rate (Nevin, 1988), which implies that, even when primary reinforcement is used, there must be conditioning to the discriminative stimuli associated with the different reinforcement rates for differential resistance to change to be present. When conditioned reinforcement is used, a second-order conditioning process must occur: conditioning of the stimuli associated with each reinforcement rate, and conditioning of secondary (conditioned) reinforcement (Shahan \& Podlesnik, 2005). This second-order conditioning is not explicitly conducted in studies that, like the present one, use money and verbal messages as reinforcement for performance. It is assumed that, given participants' history with money and verbal messages, these stimuli will act as reinforcers in the experimental situation (cf. Galizio \& Buskist, 1988).

In the present study, the verbal messages and money earnings appeared to function as reinforcers because performance in baseline and reversal training followed the scheduled 
contingencies - i.e. the baseline relations were acquired, and responding reversed when the reinforcement contingencies were reversed. Thus, there is reason to assume that the second-order conditioning described by Shahan and Podlesnik (2005) was present in the participants' history. Even if successful second-order conditioning is assumed, however, it is not likely to be homogeneous across participants. As noted by Galizio and Buskist (1988), participants typically have extended and diverse histories with secondary reinforcers by the time they come to an experiment and these differences may explain part of the differences in responding among participants exposed to the same experimental contingencies.

Another implication of using food or other primary reinforcement in behavioral momentum studies is that it allows direct manipulation the deprivation states that make reinforcement more powerful (cf. Michael, 1993). Studies using animals typically achieve effects when the animals are food-deprived. In the present study, participants' deprivation from the secondary reinforcers provided could not be so manipulated. Participants may have come into the experiment with different levels of deprivation for positive feedback and money, and thus with different susceptibility to the reinforcers used.

To add to the difficulty of using conditioned reinforcement, the schedule of reinforcement used in the present study provided both reinforcement for correct responding and purported punishment for incorrect responding. It may be argued that, although the rich condition presented reinforcement more often than the lean condition, it also presented the purported punishment more often. This argument, however, does not reflect what happened in the present study: responding under the rich condition met the accuracy criteria early in training, and thus received little feedback for incorrect responding, whereas exposure to feedback for incorrect responding was more extended in the lean condition because of the initially poor 
performance. It still remains the case, however, that a schedule of differential feedback is not identical to a schedule of reinforcement, and this discrepancy may have contributed to the unsystematic results.

Although this study found few systematic differences favoring the rich condition, this finding is consistent with the difficulty other studies have had obtaining systematic differences in the resistance to change using accuracy as a measure. The effects of reinforcement rate on accuracy have been relatively weak and sometimes non-existent (e.g., Dube \& McIlvane, 2002; Odum et al., 2005; Shahan \& Podlesnik, 2005). On the other hand, the effects of reinforcement rate on other response dimensions such as response rate have been robust (Odum et al., 2005). Though Nevin et al. (2003) emphasized that reinforcement should strengthen responding as a whole, they also found that response rates were more sensitive to differences in rate of reinforcement than accuracy. This result is consistent with findings throughout the psychological literature: measures of behavior in time such as rate, speed scores, reaction times, and latencies are highly sensitive to environmental manipulations (Chase, Doughty, \& O'Shields, 2005). The applied implications of the resistance to change of dimensions such as accuracy, however, should continue to encourage exploration of the variables affecting it (Dube \& McIlvane, 2002).

Finally, the effects of reinforcement rate on response speed were not always systematic or as predicted by behavioral momentum in the current studies. This may be because in an attempt to focus on accuracy, there was no stability or other requirements on response speeds before transitions between the phases of the study. This probably resulted in inconsistent changes because response speeds were in transition when tests, reversals, and distractors were introduced. 


\section{Future directions}

Partial class reversal (reversal of symmetry and maintenance of transitivity and combined relations) remains a largely unexplained phenomenon. Although it has been repeatedly addressed (e.g., Dube \& McIlvane, 1996; Pilgrim \& Galizio 1990, 1995), the variables controlling it have not been identified. Partial class reversal may be the result of equivalence responding not being integrated (Pilgrim \& Galizio, 1990, 1995), which allows for sources of stimulus control other than the experimental manipulation controlling responding on transitivity and combined trials (Dube \& McIlvane, 1996). This does not, however, answer the question of why poorly integrated classes in general and partial reversals in particular occur with some participants and not others. Variables such as establishing operations, participants' pre-experimental history, length of baseline training (Pilgrim \& Galizio, 1996), and duration of reversal training (Dube \& McIlvane, 1996) have been suggested as possible determinants of partial class reversals following baseline reversals. These, however, are hypotheses that await verification.

Garotti et al. (2000) proposed that, whether emergent responding reverses or not after baseline reversals depends on the behavioral momentum of original versus reversed classes. Their prediction is relevant to the present area of research because it emphasizes response strength as a determinant of partial reversal versus complete reversal. In the present study, this explanation is difficult to evaluate because of the two different baselines (rich and lean) upon which baseline reversals were implemented and because of exposure that differed in length from baseline to reversal training.

In order to better control for how well the stimulus classes are established, subsequent research examining resistance to change of response accuracy would benefit from assuring that response speed (and not only accuracy) is stable before changing experimental conditions. 
Analysis of response speeds during equivalence tests prior to baseline reversal may reveal whether the relations are integrated. For example, perhaps if response speeds for symmetry, transitivity, and combined trials are comparable, the equivalence performance would be more integrated and one would not find partial reversals. On the other hand, if response speeds vary across trial types, then the lack of integration of the three properties might result in classes more easily affected by differences in reinforcement rate.

Shahan and Podlesnik (2005)'s finding regarding the lack of effects of conditioned reinforcement on resistance to change is also worth considering in future experiments. This proves a difficult task given the problems encountered when primary reinforcement is used with typically-developed human participants. For example, Galizio and Buskist (1988) reported that participants failed to consume the reinforcers, and other contingencies (such as avoiding weight gain) controlled their behavior in ways inconsistent with the experimental manipulations. One possible alternative could consist of using conditioned reinforcers that are separated from primary reinforcement by fewer links. As discussed above, participants in this study received money contingent on their performance, but money was paid at the end of the study. Perhaps different rates of conditioned reinforcement would differentially control resistance to change if a physical reinforcer that participants could consume were provided each time a reinforcer was scheduled (e.g., Dube \& McIlvane, 2002; Pilgrim \& Galizio, 1990, 1995).

Finally, research examining the resistance to change of accuracy may need to develop accuracy measures that are more sensitive than the ones used in the experiments reported here. In Experiments 1 and 2, response accuracy was high across conditions for most participants, and this created a ceiling effect that impeded differential changes to the experimental manipulations. Experiment 3, on the other hand, increase the difficulty such that it was difficult to obtain above- 
chance accuracy levels in the initial equivalence tests. This resulted in dismissal of participants and un-analyzable data. Conditions somewhere between those used in the current experiments are needed. As suggested before, an accuracy definition that includes a time limit in its criteria could yield a measure that is more sensitive to experimental manipulations such as reinforcement rate and disruption.

\section{Conclusion}

Using a rich schedule of reinforcement during training resulted in better performance during acquisition and equivalence tests than using a lean schedule of reinforcement for most participants. The effects of the rich schedule on test performance occurred, however, only when the rich schedule was accompanied by overtraining. In addition, reversed responding was consistent with the behavioral momentum prediction only when partial reversals occurred. Participants whose responding was partially reversed also were more likely to retain reversed relations over original ones following a period without practice. The simultaneous presence of these characteristics suggest that when relational responding was not integrated as a behavioral unit (e.g., equivalence), but instead consisted of the independent relations of symmetry, transitive, and combined symmetry and transitivity, responding was more likely to be affected by reinforcement rate.

Because little is known about the variables determining the level of integration of stimulus classes, research is warranted that specifically addresses possible variables. Pilgrim and Galizio (1996) and the results of the present study indicate that the length of baseline training may be a variable worth investigating. If class integration can be controlled by manipulating length of baseline training before applying a behavioral disruptor, then we could have firmer information on the relation between class integration and the resistance to change of responding 
to stimulus classes. In addition, the finding across studies of behavioral momentum on the differences between primary and conditioned reinforcers suggests that increased attention should be paid to the kinds of conditioned reinforcers used in human studies. 


\section{References}

Barnes, D., Smeets, P. M., \& Leader, G. (1996). New procedures for establishing emergent matching performances in children and adults: implications for stimulus equivalence. In T. R. Zentall \& P. M. Smeets (Eds.). Stimulus Class Formation in Humans and Animals (pp. 153-171). Amsterdam: Elsevier.

Belfiore, P. J., Lee, D. L., Vargas, A. U., \& Skinner, C. H. (1997). Effects of high-preference single-digit mathematics problem completion on multiple-digit mathematics problem performance. Journal of Applied Behavior Analysis, 30, 327-330.

Binder, C. (1996). Behavioral fluency: Evolution of a new paradigm. The Behavior Analyst, 19, 163-197.

Brown, A. L. (1970). Transfer performance in children's oddity learning as a function of dimensional preference, shift paradigm and overtraining. Journal of Experimental Child Psychology, 9, 307-319.

Carlin, L. A., Wirth, O., \& Chase, P. N. (1998). Effects of sample-response requirements on matching-to-sample performance with humans. Experimental Analysis of Human Behavior Bulletin, 16, 2-5.

Chase, P. N. (2003). Behavioral education: pragmatic answers to questions about novelty and efficiency. In K. A. Lattal \& P. N. Chase (Eds.), Behavior Theory and Philosophy (pp. 347-367). New York: Kluwer Academic/Plenum.

Cinciripini, P. M., Epstein, L. H., \& Martin, J. E. (1979). The effects of feedback on blood pressure discrimination. Journal of Applied Behavior Analysis, 12, 345-353. 
Cooke, N. L., \& Guzaukas, R. (1993). Effects of using a ratio of new items to review items during drill and practice: Three experiments. Education and Treatment of Children, 16, 213-235.

Dihoff, R. E., Brosvic, G. M., Epstein, M. L, \& Cook, J. M. (2004). Provision of feedback during preparation for academic testing: Learning is enhanced by immediate but not delayed feedback. The Psychological Record, 54, 207-231.

Dougherty, K. M., \& Johnston, J. M. (1996). Overlearning, fluency, and automaticity. The Behavior Analyst, 19, 289-292.

Doughty, A. H., Cirino, S., Mayfield, K. H., da Silva, S. P., Okouchi, H., \& Lattal, K. A. (2005). Effects of behavioral history on resistance to change. The Psychological Record, 55, 315330.

Doughty, S. S., Chase, P. N., \& O’Shields, E. M. (2004). Effects of rate building on fluent performance: A review and commentary. The Behavior Analyst, 27, 7-23.

Driskell, J. E., Willis, R. P., \& Copper, C. (1992). Effect of overlearning on retention. Journal of Applied Psychology, 77, 625-622.

Dube, W. V., \& McIlvane, W. J. (1996). Some implications of a stimulus control topography analysis for emergent behavior and stimulus classes. In T. R. Zentall \& P. M. Smeets (Eds.). Stimulus Class Formation in Humans and Animals (pp. 197-218). Amsterdam: Elsevier.

Dube, W. V., \& McIlvane, W. J. (2001). Behavioral momentum in computer-presented discriminations in individuals with severe mental retardation. Journal of Applied Behavior Analysis, 75, 15-23. 
Dube, W. V, \& McIlvane, W. J. (2002). Reinforcer rate and stimulus control in discrimination reversal learning. The Psychological Record, 52, 405-416.

Ericsson, K. A., Krampe, R. T., \& Tesch-Romer, C. (1993). The role of deliberate practice in the acquisition of expert performance. Psychological Review, 100, 363-406.

Fath, S. J., Fields, L., Malott, M. K., \& Grossett, D. (1983). Response rate, latency, and resistance to change. Journal of the Experimental Analysis of Behavior, 39, 267-274.

Fields, L., Adams, B. J., Verhave, T., \& Newman, S. (1990). The effects of nodality on the formation of equivalence classes. Journal of the Experimental Analysis of Behavior, 53, $345-358$.

Fields, L., Landon-Jimenez, D. V., Buffington, D. M., \& Adams, B. J. (1995). Maintained nodaldistance effects in equivalence classes. Journal of the Experimental Analysis of Behavior, $64,129-145$.

Fields, L., Reeve, K. F., Rosen, D., Varelas, A., Adams, B. J., Belanich, J., \& Hobbie, S. A. (1997). Using the simultaneous protocol to study equivalence class formation: The facilitating effects of nodal number and size of previously established equivalence classes. Journal of the Experimental Analysis of Behavior, 67, 367-389.

Fitzgerald, D. (2001). The Effects of Fluency in the Acquisition of Conditional, Symmetric, and Equivalence Relations on the Emergence of Derived Relational Responding and the Contextual Control of Relational Behavior. Unpublished doctoral dissertation, University of Nevada, Reno.

Galizio, M., \& Buskist, W. (1988). Laboratory lore and research practices in the experimental analysis of human behavior: selecting reinforcers and arranging contingencies. The Behavior Analyst, 11, 65-69. 
Garotti, M., de Souza, D. G., de Rose, J. C., Molina, R. C., \& Gil, M. S. (2000). Reorganization of equivalence classes after reversal of baseline relations. The Psychological Record, 50, $35-48$.

Green, G., \& Saunders, R. (1998). Stimulus equivalence. In K. A. Lattal \& M. Perone (Eds.), Handbook of Research Methods in Human Operant Behavior (pp. 229-262). New York, Plenum Press.

Harrison, R. J., \& Green, G. (1990). Development of conditional and equivalence relations without differential consequences. Journal of the Experimental Analysis of Behavior, 54, 225-237.

Johnson, K. R., \& Layng, T. V. J. (1992). Breaking the structuralist barrier: Literacy and numeracy with fluency. American Psychologist, 47, 1475-1490.

Joyce, J. H., \& Chase, P. N. (1990). Effects of response variability on the sensitivity of rulegoverned behavior. Journal of the Experimental Analysis of Behavior, 54, 251-262.

Kennedy, C. H., Itkonen, T., \& Lindquist, K. (1994). Nodality effects during equivalence class formation: an extension to sight-word reading and concept development. Journal of Applied Behavior Analysis, 27, 673-683.

Mace, F. C., Hock, M. L., Lalli, J. S., West, B. J., Belfiore, P., Pinter, E., \& Brown, D. K. (1988). Behavioral momentum in the treatment of noncompliance. Journal of Applied Behavior Analysis, 21, 123-141.

Mace, C. F., Lalli, J. S., Shea, M. C., Lalli, E. P., West, B. J., Roberts, M., \& Nevin, J. A. (1990). The momentum of human behavior in a natural setting. Journal of the Experimental Analysis of Behavior, 54, 163-172.

Michael, J. (1993). Establishing operations. The Behavior Analyst, 16, 191-206. 
Nevin, J. A. (1988). Behavioral momentum and the partial reinforcement effect. Psychological Bulletin, 103, 44-56.

Nevin, J. A., Mandell, C., \& Atak, J. R. (1983). The analysis of behavioral momentum. Journal of the Experimental Analysis of Behavior, 39, 49-59.

Nevin, J. A., Milo, J., Odum, A. L., \& Shahan, T. A. (2003). Accuracy of discrimination, rate of responding, and resistance to change. Journal of the Experimental Analysis of Behavior, 79, 307-321.

Odum, A. L., Shahan, T. A., \& Nevin, J. A. (2005). Resistance to change of forgetting functions and response rates. Journal of the Experimental Analysis of Behavior, 84, 65-75.

Pilgrim, C., \& Galizio, M. (1990). Relations between baseline contingencies and equivalence probe performances. Journal of the Experimental Analysis of Behavior, 54, 213-224.

Pilgrim, C., \& Galizio, M. (1995). Reversal of baseline relations and stimulus equivalence: I. Adults. Journal of the Experimental Analysis of Behavior, 63, 225-238.

Pilgrim, C., Chambers, L., \& Galizio, M. (1995). Reversal of baseline relations and stimulus equivalence: II. Children. Journal of the Experimental Analysis of Behavior, 63, 239-254.

Pilgrim, C., \& Galizio, M. (1996). Stimulus equivalence: a class of correlations, or a correlation of classes? In T. R. Zentall \& P. M. Smeets (Eds.). Stimulus Class Formation in Humans and Animals (pp. 173-195). Amsterdam: Elsevier.

Podlesnik, C. A., \& Chase, P. N. (in press). Sensitivity and strength: effects of instructions on resistance to change. The Psychological Record.

Shahan, T. A., \& Podlesnik, C. A. (2005). Rate of conditioned reinforcement affects observing rate but not resistance to change. Journal of the Experimental Analysis of Behavior, 84, 117. 
Sidman, M. (2000). Equivalence relations and the reinforcement contingency. Journal of the Experimental Analysis of Behavior, 74, 127-146.

Spencer, T. J., \& Chase, P. N. (1996). Speed analyses of stimulus equivalence. Journal of the Experimental Analysis of Behavior, 65, 643-659.

Spradlin, J. E., Saunders, K. J., \& Saunders, R. r. (1992). The stability of equivalence classes. In S. C. Hayes \& L. J. Hayes (Eds.), Understanding Verbal Relations (pp. 29-42). Reno, NV: Context Press.

Walker, V. (2005). The Role of Reinforcement Rate on Fluency. Unpublished master's thesis, West Virginia University.

Wilkie, D. M., Summers, R. J., \& Spetch, M. L. (1981). Effect of delay-interval stimuli on delayed symbolic matching to sample in the pigeon. Journal of the Experimental Analysis of Behavior, 35, 153-160.

Wirth, O., \& Chase, P. N. (2002). Stability of functional equivalence and stimulus equivalence: Effects of baseline reversals. Journal of the Experimental Analysis of Behavior, 77, 2947.

Wulfert, E., \& Hayes, S. C. (1988). The transfer of conditional ordering response through conditional equivalence classes. Journal of the Experimental Analysis of Behavior, 50, $125-144$.

Young, K. R., West, R. P., Howard, V. F., \& Whitney, R. (1986). Acquisition, fluency training, generalization, and maintenance of dressing skills of two developmentally disabled children. Education and Treatment of Children, 9, 16-29. 


\section{Table 1}

Stages of Experiments 1 and 2.

\begin{tabular}{|c|c|c|}
\hline Stage & \multicolumn{2}{|c|}{ Description } \\
\hline \multirow{4}{*}{ Baseline training } & Rich Schedule-Stimulus Set One & Lean Schedule-Stimulus Set Two \\
\hline & Training of $\mathrm{AB}$ relations & Training of $\mathrm{AB}$ relations \\
\hline & Training of $\mathrm{BC}$ relations & Training of $\mathrm{BC}$ relations \\
\hline & $\mathrm{AB}$ and $\mathrm{BC}$ relations intermixed & $\mathrm{AB}$ and $\mathrm{BC}$ relations intermixed \\
\hline Tests of stimulus equivalence & Baseline and test blocks alternate. & Baseline and test blocks alternate. \\
\hline Reversal training (disruption) & $\mathrm{AB}$ relations for targeted classes & $\mathrm{AB}$ relations for targeted classes \\
\hline & reversed (baseline blocks only). & reversed (baseline blocks only). \\
\hline Post-reversal tests & $\begin{array}{l}\text { Reversed baseline and test blocks } \\
\text { alternate. }\end{array}$ & $\begin{array}{l}\text { Reversed baseline and test blocks } \\
\text { alternate. }\end{array}$ \\
\hline Retention tests & Test blocks only. & Test blocks only. \\
\hline
\end{tabular}


Table 2

Composition of Blocks and Trials for Training and Equivalence Testing of Experiments 1 and 2.

\begin{tabular}{|c|c|c|}
\hline Type of blocks & $\begin{array}{c}\text { Trial composition (sample: } \\
\text { comparisons) }\end{array}$ & $\begin{array}{c}\text { Number of presentations } \\
\text { within a block/Total trials } \\
\text { per block }\end{array}$ \\
\hline \multicolumn{3}{|l|}{ Baseline relations } \\
\hline \multirow[t]{3}{*}{$\mathrm{AB}$} & $\mathrm{A} 1: B 1, \mathrm{~B} 2, \mathrm{~B} 3$ & $12 / 36$ \\
\hline & $\mathrm{A} 2: \mathrm{B} 1, \mathrm{~B} 2, \mathrm{~B} 3$ & $12 / 36$ \\
\hline & A3: B1, B2, B3 & $12 / 36$ \\
\hline \multirow[t]{3}{*}{$\mathrm{BC}$} & $\mathrm{B} 1: C 1, \mathrm{C} 2, \mathrm{C} 3$ & $12 / 36$ \\
\hline & $\mathrm{B} 2: \mathrm{C} 1, C 2, \mathrm{C} 3$ & $12 / 36$ \\
\hline & B3: C1, C2, C3 & $12 / 36$ \\
\hline \multirow[t]{6}{*}{ Combined $\mathrm{AB}$ and $\mathrm{BC}$ relations } & $\mathrm{A} 1: B 1, \mathrm{~B} 2, \mathrm{~B} 3$ & $6 / 36$ \\
\hline & $\mathrm{A} 2: \mathrm{B} 1, B 2, \mathrm{~B} 3$ & $6 / 36$ \\
\hline & A3: B1, B2, B3 & $6 / 36$ \\
\hline & $\mathrm{B} 1: C 1, \mathrm{C} 2, \mathrm{C} 3$ & $6 / 36$ \\
\hline & $\mathrm{B} 2: \mathrm{C} 1, C 2, \mathrm{C} 3$ & $6 / 36$ \\
\hline & B3: C1, C2, C3 & $6 / 36$ \\
\hline \multicolumn{3}{|l|}{ Test blocks } \\
\hline \multirow[t]{6}{*}{ BA and CB (symmetry) } & $\mathrm{B} 1: \mathrm{A} 1, \mathrm{~A} 2, \mathrm{~A} 3$ & $3 / 36$ \\
\hline & $\mathrm{B} 2: \mathrm{A} 1, \mathrm{~A} 2, \mathrm{~A} 3$ & $3 / 36$ \\
\hline & B3: A1, A2, A3 & $3 / 36$ \\
\hline & C1: B1, B2, B3 & $3 / 36$ \\
\hline & C2: B1, B2, B3 & $3 / 36$ \\
\hline & C3: B1, B2, B3 & $3 / 36$ \\
\hline \multirow[t]{3}{*}{ AC (transitivity) } & $\mathrm{A} 1: \mathrm{C} 1, \mathrm{C} 2, \mathrm{C} 3$ & $3 / 36$ \\
\hline & $\mathrm{A} 2: \mathrm{C} 1, \mathrm{C} 2, \mathrm{C} 3$ & $3 / 36$ \\
\hline & A3: C1, C2, C3 & $3 / 36$ \\
\hline \multirow[t]{3}{*}{ CA (combined) } & $\mathrm{C} 1: \mathrm{A} 1, \mathrm{~A} 2, \mathrm{~A} 3$ & $3 / 36$ \\
\hline & $\mathrm{C} 2: \mathrm{A} 1, \mathrm{~A} 2, \mathrm{~A} 3$ & $3 / 36$ \\
\hline & C3: A1, A2, A3 & $3 / 36$ \\
\hline
\end{tabular}

Note. The italicized comparison stimuli indicate reinforced responses during training. 
Table 3

Composition of Blocks and Trials for Reversal Training and Post-reversal Tests of Experiments

1 and 2.

\begin{tabular}{ccc}
\hline Condition & $\begin{array}{c}\text { Trial composition (sample: } \\
\text { comparisons) }\end{array}$ & $\begin{array}{c}\text { Number of presentations } \\
\text { within a block/Total trials } \\
\text { per block }\end{array}$ \\
\hline Reversal of AB relations & & \\
AB (reversed) & A1: B1, B2, B3 & $12 / 36$ \\
& A2: B1, B2, B3 & $12 / 36$ \\
& A3: B1, B2, B3 & $12 / 36$ \\
Test blocks (postreversal) & & \\
& & $3 / 36$ \\
BA and CB (symmetry) & B1: A1, A2, A3 & $3 / 36$ \\
& B2: A1, A2, A3 & $3 / 36$ \\
& B3: A1, A2, A3 & $3 / 36$ \\
& C1: B1, B2, B3 & $3 / 36$ \\
& C2: B1, B2, B3 & $3 / 36$ \\
C3: B1, B2, B3 & $3 / 36$ \\
AC (transitivity) & A1: C1, C2, C3 & $3 / 36$ \\
& A2: C1, C2, C3 & $3 / 36$ \\
& A3: C1, C2, C3 & $3 / 36$ \\
& & $3 / 36$ \\
CA (combined) & C2: A1, A2, A3 & $3 / 36$ \\
\hline & C3: A1, A2, A3 & \\
& & \\
& &
\end{tabular}

Note. The italicized comparison stimuli indicate reinforced responses during training. 
Table 4.

Number of Blocks Needed to Reach Mastery Criteria in AB and BC training for Each Experimental Condition in Experiment 1.

\begin{tabular}{lcccccc}
\hline Participant & \multicolumn{2}{c}{ AB Training } & \multicolumn{2}{c}{ BC Training } & \multicolumn{2}{c}{ Total } \\
& Rich & Lean & Rich & Lean & Rich & Lean \\
\hline 300 & 6 & 11 & 2 & 2 & 8 & 13 \\
221 & 2 & 4 & 2 & 2 & 4 & 6 \\
788 & 7 & 10 & 2 & 2 & 9 & 12 \\
184 & 4 & 3 & 1 & 2 & 5 & 5 \\
311 & 4 & 4 & 2 & 5 & 6 & 9 \\
425 & 2 & 3 & 3 & 4 & 5 & 7 \\
\hline
\end{tabular}

Table 5.

Mean Response Speeds to Correct and Incorrect Comparison Stimuli during the First Two

Blocks of Initial Testing for Experiment 1.

\begin{tabular}{|c|c|c|c|c|c|}
\hline \multirow{3}{*}{\multicolumn{2}{|c|}{ Participant and Type of Relation }} & \multicolumn{4}{|c|}{ Responses/second } \\
\hline & & \multicolumn{2}{|c|}{ Rich } & \multicolumn{2}{|c|}{ Lean } \\
\hline & & Correct & Incorrect & Correct & Incorrect \\
\hline \multirow[t]{3}{*}{184} & Symmetry & .87 & & .61 & .16 \\
\hline & Transitivity & .54 & & .28 & .22 \\
\hline & Combined & .57 & & .37 & .51 \\
\hline \multirow[t]{3}{*}{311} & Symmetry & .79 & & .40 & \\
\hline & Transitivity & .47 & & .35 & .27 \\
\hline & Combined & .58 & & .55 & 1.12 \\
\hline \multirow[t]{3}{*}{788} & Symmetry & .86 & .33 & .83 & \\
\hline & Transitivity & $\mathrm{n} / \mathrm{a}^{1}$ & .61 & .53 & \\
\hline & Combined & $\mathrm{n} / \mathrm{a}$ & .76 & .69 & \\
\hline \multirow[t]{3}{*}{425} & Symmetry & .96 & & .53 & .37 \\
\hline & Transitivity & .70 & & .30 & .38 \\
\hline & Combined & .71 & & .35 & .33 \\
\hline \multirow[t]{3}{*}{300} & Symmetry & .78 & .72 & .89 & .48 \\
\hline & Transitivity & .51 & .88 & .37 & .78 \\
\hline & Combined & .64 & .77 & .70 & .84 \\
\hline \multirow[t]{3}{*}{221} & Symmetry & .66 & & .86 & .16 \\
\hline & Transitivity & .64 & & .55 & .30 \\
\hline & Combined & .64 & & .52 & \\
\hline
\end{tabular}


${ }^{1}$ No correct trials occurred.

Table 6.

Number of Blocks to Criterion for Reversal Training for Experiment 1.

\begin{tabular}{ccc}
\hline Participant & Rich & Lean \\
\hline 184 & 2 & 1 \\
311 & 1 & 1 \\
788 & 2 & 2 \\
425 & 2 & 2 \\
300 & 2 & 2 \\
221 & 1 & 2 \\
\hline
\end{tabular}

Table 7.

Mean Response Speeds to Correct and Incorrect Comparison Stimuli during the First Two

Blocks of Reversal Training for Experiment 1.

\begin{tabular}{lllll}
\hline & \multicolumn{4}{c}{ Responses/second } \\
& \multicolumn{2}{c}{ Rich } & \multicolumn{2}{c}{ Lean } \\
Participant & Correct & Incorrect & Correct & Incorrect \\
\hline 184 & .80 & .42 & .99 & \\
311 & 1.52 & & 1.12 & \\
788 & 1.00 & .79 & .97 & .72 \\
425 & 1.07 & .62 & .88 & .86 \\
300 & 1.00 & .81 & 1.25 & .65 \\
221 & .88 & & 1.02 & .62 \\
\hline
\end{tabular}

Note. Incorrect trials are reported only if accuracy was below $90 \%$. 
Table 8.

Mean Response Speeds to Correct and Incorrect Comparison Stimuli during the First Two

Blocks of Post-Reversal Tests for Experiment 1.

\begin{tabular}{|c|c|c|c|c|c|}
\hline \multirow{3}{*}{\multicolumn{2}{|c|}{ Participant and Type of Relation }} & \multicolumn{4}{|c|}{ Responses/second } \\
\hline & & \multicolumn{2}{|c|}{ Rich } & \multicolumn{2}{|c|}{ Lean } \\
\hline & & Correct & Incorrect & Correct & Incorrect \\
\hline \multirow[t]{3}{*}{184} & Symmetry & .56 & .28 & .71 & .16 \\
\hline & Transitivity & .66 & .47 & .73 & .49 \\
\hline & Combined & .83 & .36 & .55 & .39 \\
\hline \multirow[t]{3}{*}{311} & Symmetry & 1.00 & & .78 & \\
\hline & Transitivity & .95 & & .88 & \\
\hline & Combined & 1.09 & & .88 & \\
\hline \multirow[t]{3}{*}{788} & Symmetry & 1.12 & .72 & .90 & .64 \\
\hline & Transitivity & .57 & .73 & .57 & .53 \\
\hline & Combined & .62 & .74 & .45 & .95 \\
\hline \multirow[t]{3}{*}{425} & Symmetry & 1.02 & & .62 & \\
\hline & Transitivity & .70 & & 48 & \\
\hline & Combined & .76 & & .38 & \\
\hline \multirow[t]{3}{*}{300} & Symmetry & .99 & .66 & 1.00 & .73 \\
\hline & Transitivity & .44 & .67 & .45 & .60 \\
\hline & Combined & .79 & .66 & .48 & .50 \\
\hline \multirow[t]{3}{*}{221} & Symmetry & .46 & .44 & .68 & \\
\hline & Transitivity & .49 & .41 & .46 & .23 \\
\hline & Combined & .56 & .48 & .65 & \\
\hline
\end{tabular}

Note. Incorrect trials are reported only if accuracy was below $90 \%$. 
Table 9.

Response Speeds to Correct and Incorrect Comparison Stimuli during the First Two Blocks of Retention Tests for Experiment 1.

\begin{tabular}{|c|c|c|c|c|c|}
\hline \multirow{3}{*}{\multicolumn{2}{|c|}{ Participant and Type of Relation }} & \multicolumn{4}{|c|}{ Responses/second } \\
\hline & & \multicolumn{2}{|c|}{ Rich } & \multicolumn{2}{|c|}{ Lean } \\
\hline & & Correct & Incorrect & Correct & Incorrect \\
\hline \multirow[t]{3}{*}{184} & Symmetry & .93 & & .84 & .55 \\
\hline & Transitivity & .57 & & .50 & .48 \\
\hline & Combined & .61 & & .99 & .62 \\
\hline \multirow{3}{*}{311} & Symmetry & 1.09 & 1.11 & .62 & .09 \\
\hline & Transitivity & .69 & .83 & .98 & \\
\hline & Combined & .97 & 1.57 & 1.02 & \\
\hline \multirow[t]{3}{*}{788} & Symmetry & .87 & 1.35 & .75 & .18 \\
\hline & Transitivity & .72 & & .72 & .79 \\
\hline & Combined & .88 & & .77 & .44 \\
\hline \multirow[t]{3}{*}{425} & Symmetry & .75 & .80 & .72 & .70 \\
\hline & Transitivity & 1.09 & .59 & .65 & .57 \\
\hline & Combined & .85 & .63 & .81 & .89 \\
\hline \multirow[t]{3}{*}{300} & Symmetry & .89 & .79 & 1.07 & \\
\hline & Transitivity & .73 & .65 & .58 & \\
\hline & Combined & .94 & .85 & .60 & \\
\hline \multirow[t]{3}{*}{221} & Symmetry & 1.09 & & 1.13 & 94 \\
\hline & Transitivity & .79 & & .89 & 1.15 \\
\hline & Combined & .95 & & 1.10 & 1.17 \\
\hline
\end{tabular}

Table 10.

Number of Blocks Needed to Reach Mastery Criteria in AB and BC training for Each

Experimental Condition in Experiment 2.

\begin{tabular}{lcccccc}
\hline & \multicolumn{2}{c}{ AB Training } & \multicolumn{2}{c}{ BC Training } & \multicolumn{2}{c}{ Total } \\
Participant & Rich & Lean & Rich & Lean & Rich & Lean \\
\hline 147 & 3 & 3 & 2 & 1 & 5 & 4 \\
522 & 4 & 6 & 3 & 1 & 7 & 7 \\
556 & 2 & 6 & 1 & 2 & 3 & 8 \\
633 & 2 & 2 & 2 & 2 & 4 & 4 \\
854 & 2 & 2 & 2 & 2 & 4 & 4 \\
987 & 3 & 3 & 1 & 1 & 4 & 4 \\
\hline
\end{tabular}


Table 11.

Amount of overtraining in the $A B$ and $B C$ training conditions in Experiment 2.

\begin{tabular}{ccccc}
\hline & & \multicolumn{3}{c}{ Amount of Overtraining } \\
Participant & Criterion for Overtraining & AB Training & BC Training & Combined training \\
\hline 147 & Absolute & 0 blocks & 0 blocks & 2 blocks \\
522 & Relative & $25 \%$ & $100 \%$ & $0 \%$ \\
556 & Absolute & 3 blocks & 1 block & 0 blocks \\
633 & Relative & $0 \%$ & $0 \%$ & $200 \%$ \\
854 & Relative & $0 \%$ & $0 \%$ & $0 \%$ \\
987 & Absolute & 0 blocks & 0 blocks & 1 block \\
\hline
\end{tabular}

Table 12.

Mean Response Speeds to Comparison Stimuli for Correct and Incorrect Trials during the First

Two Blocks of Initial Testing for Experiment 2.

\begin{tabular}{|c|c|c|c|c|c|}
\hline \multirow{3}{*}{\multicolumn{2}{|c|}{ Participant and Type of Relation }} & \multicolumn{4}{|c|}{ Responses/second } \\
\hline & & \multicolumn{2}{|c|}{ Rich } & \multicolumn{2}{|c|}{ Lean } \\
\hline & & Correct & Incorrect & Correct & Incorrect \\
\hline \multirow[t]{3}{*}{147} & Symmetry & .76 & & .90 & \\
\hline & Transitivity & 27 & .48 & .54 & .49 \\
\hline & Combined & .54 & .86 & .51 & .70 \\
\hline \multirow[t]{3}{*}{522} & Symmetry & .62 & .16 & .92 & \\
\hline & Transitivity & .34 & .49 & .52 & \\
\hline & Combined & .40 & .91 & .64 & \\
\hline \multirow[t]{3}{*}{556} & Symmetry & .87 & & .71 & \\
\hline & Transitivity & .62 & & .77 & \\
\hline & Combined & .79 & .04 & .99 & \\
\hline \multirow[t]{3}{*}{633} & Symmetry & .65 & & .63 & \\
\hline & Transitivity & .45 & .15 & .55 & \\
\hline & Combined & 60 & & .67 & \\
\hline \multirow[t]{3}{*}{854} & Symmetry & .51 & & .91 & \\
\hline & Transitivity & .34 & .20 & .69 & \\
\hline & Combined & 42 & .09 & .93 & \\
\hline \multirow[t]{3}{*}{987} & Symmetry & 97 & & .90 & \\
\hline & Transitivity & .66 & .63 & .75 & .16 \\
\hline & Combined & .64 & .39 & .75 & .49 \\
\hline
\end{tabular}

Note. Incorrect trials are reported only if accuracy was below $90 \%$. 
Table 13.

Number of Blocks Needed to Reach Mastery Criteria for Each Condition during Reversal

Training for Experiment 2.

\begin{tabular}{lcc}
\hline Participant & Rich & Lean \\
\hline 147 & 1 & 1 \\
522 & 2 & 1 \\
556 & 2 & 1 \\
633 & 2 & 2 \\
854 & 2 & 2 \\
987 & 1 & 1 \\
\hline
\end{tabular}

Table 14.

Mean Response Speeds to Correct and Incorrect Comparison Stimuli during the First Two Blocks of Reversal Training for Experiment 2.

\begin{tabular}{lllll}
\hline & \multicolumn{4}{c}{ Responses/second } \\
& \multicolumn{2}{c}{ Rich } & \multicolumn{2}{c}{ Lean } \\
Participant & Correct & Incorrect & Correct & Incorrect \\
\hline 147 & 1.09 & & 1.16 & \\
522 & .81 & .52 & .96 & \\
556 & 1.17 & .52 & 1.04 & \\
633 & .78 & .51 & .88 & .54 \\
854 & .94 & .59 & 1.10 & .79 \\
987 & 1.34 & & 1.29 & \\
\hline
\end{tabular}

Note. Incorrect trials are reported only if accuracy was below $90 \%$. 
Table 15 .

Mean Response Speeds to Correct and Incorrect Comparison Stimuli during the First Two

Blocks of Post-reversal Tests for Experiment 2.

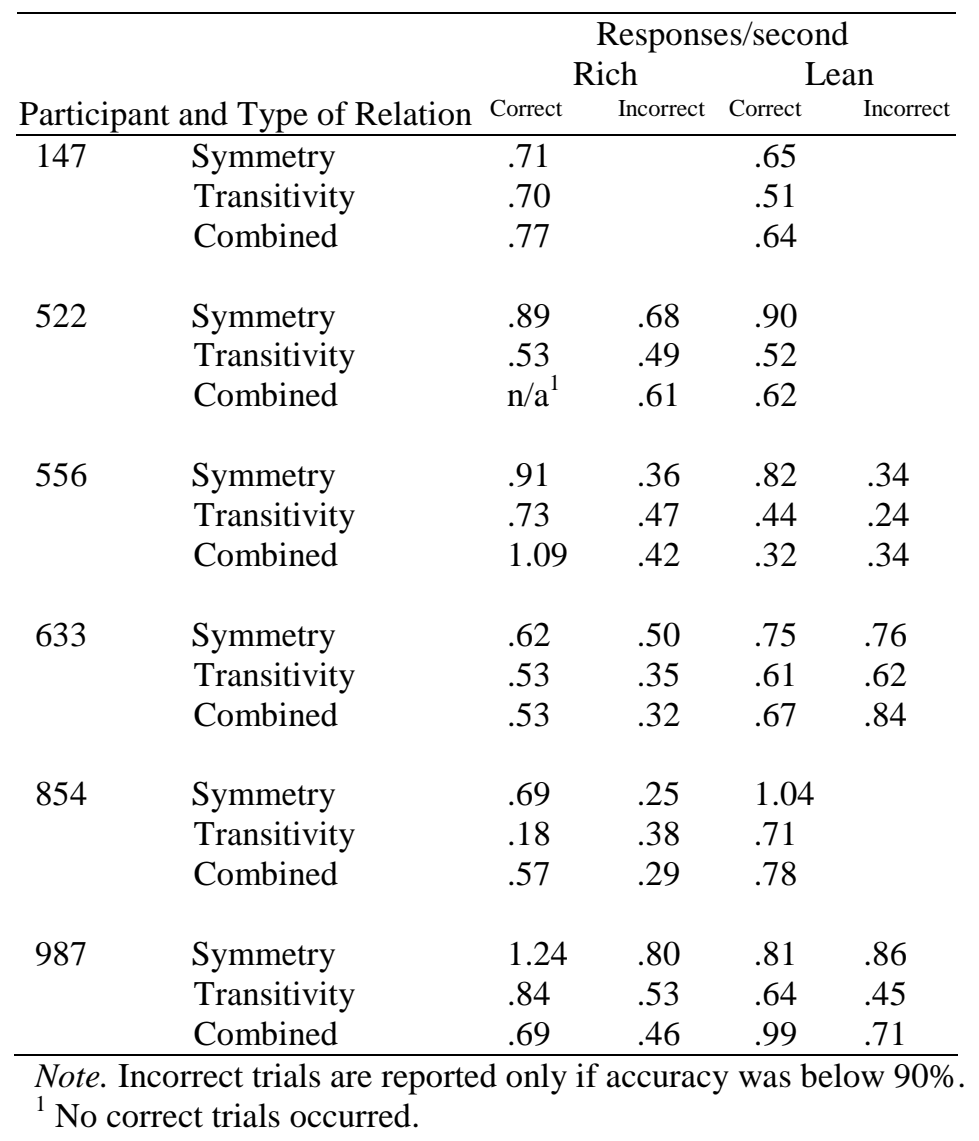


Table 16.

Mean Response Speeds to Comparison Stimuli for Correct and Incorrect Trials during the First

Two Blocks of Retention Tests for Experiment 2.

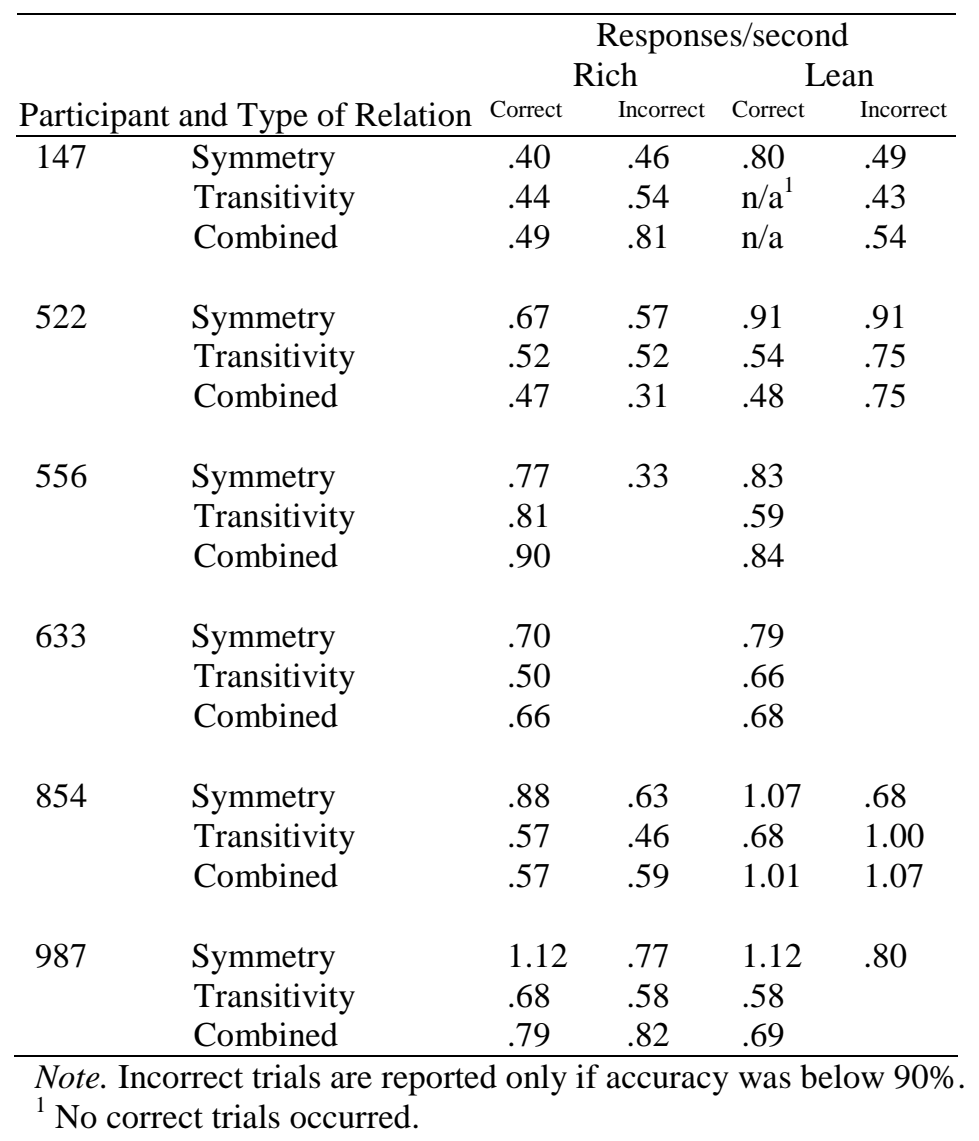


Table 17.

Stages of the Experimental Design for Experiment 3.

\begin{tabular}{lll}
\hline \multicolumn{1}{c}{ Stage } & & \multicolumn{2}{c}{ Description } \\
\hline 1. Baseline training & Rich Schedule-Stimulus Set One & \multicolumn{1}{c}{ Lean Schedule-Stimulus Set Two } \\
& AB training & AB training \\
& BC training & BC training \\
& CD training & CD training \\
& DE training & DE training \\
& AB, BC, CD, and DE training & AB, BC, CD and DE training \\
& Final training and test blocks & Final training and test blocks \\
& alternate. & alternate. \\
& & \\
3. Tests of stimulus equivalence & Training and test blocks alternate; & Training and test blocks alternate; \\
& stimuli presented during delay. & stimuli presented during delay. \\
& & \\
4. Retention tests & Test blocks only. & Test blocks only. \\
\hline
\end{tabular}

Table 18.

Number of Trials per Block for Each Trained and Tested Conditional Relation at Each Stage of Baseline Training and During Testing in Experiment 3.

\begin{tabular}{|c|c|c|c|c|c|c|c|c|c|c|c|c|c|c|c|c|}
\hline & \multicolumn{16}{|c|}{ Trials per Block } \\
\hline Training & & $\mathrm{AB}$ & & & $\mathrm{BC}$ & & & $\mathrm{Cl}$ & & & & DE & & & Total & \\
\hline $\mathrm{AB}$ & & 36 & & & -- & & & - & & & & -- & & & 36 & \\
\hline $\mathrm{BC}$ & & 18 & & & 36 & & & - & & & & -- & & & 54 & \\
\hline $\mathrm{CD}$ & & 9 & & & 9 & & & 36 & & & & -- & & & 54 & \\
\hline DE (1) & & 6 & & & 12 & & & 18 & & & & 36 & & & 72 & \\
\hline $\mathrm{DE}(2)$ & & 3 & & & 15 & & & 18 & & & & 36 & & & 72 & \\
\hline Final & & 18 & & & 18 & & & 18 & & & & 18 & & & 72 & \\
\hline Total & & 90 & & & 90 & & & 90 & & & & 90 & & & 360 & \\
\hline Testing & $\mathrm{AC}$ & $\mathrm{AD}$ & $\mathrm{AE}$ & $\mathrm{BA}$ & $\mathrm{BD}$ & $\mathrm{BE}$ & $\mathrm{CA}$ & $\mathrm{CB}$ & $\mathrm{CE}$ & $\mathrm{DA}$ & $\overline{\mathrm{DB}}$ & $\overline{\mathrm{DC}}$ & EA & EB & $\overline{\mathrm{EC}}$ & $\overline{E D}$ \\
\hline & 3 & 3 & 3 & 3 & 3 & 3 & 3 & 3 & 3 & 3 & 3 & 3 & 3 & 3 & 3 & 3 \\
\hline
\end{tabular}


Table 19.

Number of Blocks Needed to Reach Mastery Criteria during Training for Each Experimental Condition in Experiment 3.

\begin{tabular}{cccc}
\hline Participant and Type of Relation & Rich & Lean \\
\hline 378 & AB & 3 & 4 \\
& BC & 2 & 2 \\
& CD & 1 & 2 \\
458 & DE & 1 & 2 \\
& AB & 4 & \\
& BC & 1 & 1 \\
& CD & 2 & 2 \\
506 & DE & 1 & 1 \\
& & & \\
& AB & 2 & 7 \\
& BC & 1 & 2 \\
& CD & 1 & 2 \\
& DE & 1 & 2 \\
\hline
\end{tabular}

Table 20.

Mean Response Speeds to Comparison Stimuli in Correct Trials during the Last Block of

Baseline Training in Experiment 3.

\begin{tabular}{lcc}
\hline Participant & Rich & Lean \\
\hline 378 & .62 & .76 \\
458 & .84 & .99 \\
506 & 1.13 & 1.02
\end{tabular}

Note. Response speeds for incorrect trials are not showed because accuracy was above $90 \%$ for all participants. 
Table 21.

Mean Response Speed to Comparison Stimuli during the First Two Blocks of Equivalence Tests Separated by Nodal Distance for Experiment 3.

\begin{tabular}{lllcll}
\hline Participant & Type of Relation & \multicolumn{2}{c}{ Rich } & \multicolumn{2}{c}{ Lean } \\
& & Correct & Incorrect & Correct & Incorrect \\
\hline 378 & Symmetry & .43 & .32 & .68 & \\
& 1 node & .20 & .26 & .37 & .40 \\
& 2 nodes & .24 & .09 & .28 & \\
& 3 nodes & .19 & .34 & .20 & .30 \\
& & & & & \\
458 & Symmetry & .32 & .10 & .52 & .33 \\
& 1 node & .19 & .15 & .28 & .17 \\
& 2 nodes & .14 & .13 & .14 & .18 \\
& 3 nodes & .12 & .15 & .34 & .18 \\
506 & & & & & \\
& Symmetry & .71 & & .62 & .06 \\
& 1 node & .58 & .54 & .39 & .34 \\
& 2 nodes & .60 & & .28 & .26 \\
& 3 nodes & .49 & & .31 & .26 \\
\hline
\end{tabular}

Table 22.

Accuracy Levels for Baseline Training and Disruption Training Across Conditions for

Experiment 3.

\begin{tabular}{lcccc}
\hline & \multicolumn{2}{c}{ Rich } & \multicolumn{2}{c}{ Lean } \\
Participant & Baseline training & Disruption training & Baseline training & Disruption training \\
\hline 378 & 97 & 90 & 97 & 99 \\
458 & 100 & 94 & 100 & 97 \\
506 & 99 & 100 & 94 & 99 \\
\hline
\end{tabular}

Table 23 .

Response Speeds for the Last Block of Baseline Training and the First Block of Disruption

Training Across Conditions for Experiment 3.

\begin{tabular}{lcccc}
\hline & \multicolumn{2}{c}{ Rich } & \multicolumn{2}{c}{ Lean } \\
Participant & Baseline training & Disruption training & Baseline training & Disruption training \\
\hline 378 & .62 & 1.01 & .76 & 1.08 \\
458 & .95 & .56 & .79 & .58 \\
506 & 1.13 & .84 & 1.02 & .61 \\
\hline
\end{tabular}


Table 24.

Mean Response Speeds for Correct and Incorrect Trials during the First Two Blocks of Retention Tests for Experiment 3.

\begin{tabular}{llclc}
\hline Participant & \multicolumn{2}{c}{ Rich } & \multicolumn{2}{c}{ Lean } \\
& Correct & Incorrect & Correct & Incorrect \\
\hline 378 & .38 & .49 & .56 & \\
458 & .38 & & .60 & .29 \\
506 & .84 & & .91 & \\
\end{tabular}

Note. Speed for incorrect responding is reported only if performance was below $90 \%$ accuracy. 
Figure 1. Stimuli used in Experiments 1 and 2. Letters indicate sets of comparison stimuli; numbers indicate the stimulus classes (original stimuli from Wirth and Chase, 2002).

\begin{tabular}{|c|c|c|c|c|c|c|c|}
\hline \multicolumn{4}{|c|}{ Stimulus set I } & & \multicolumn{3}{|c|}{ Stimulus set II } \\
\hline & 1 & 2 & 3 & & 4 & 5 & 6 \\
\hline $\mathrm{A}$ & 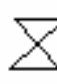 & & $\stackrel{(\Omega)}{\leftrightharpoons}$ & A & & 8 & एव \\
\hline$B$ & & 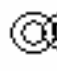 & $\mathbb{4}$ & $\mathrm{B}$ & & 氖 & 5 \\
\hline C & 10 & 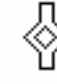 & 田 & $\mathrm{C}$ & $\square$ & $\stackrel{0}{\square}$ & $\mathrm{l} / \mathrm{P}$ \\
\hline
\end{tabular}


Figure 2. Percent accuracy on all test trials during the first two blocks of initial tests for each participant and condition for Experiment 1. Accuracy is shown for each type of samplecomparison relations (B1A1, B2A2, B3A3, C1B1, C2B2, C3B3, A1C1, A2C2, A3C3, C1A1, $\mathrm{C} 2 \mathrm{~A} 2$, and $\mathrm{C} 3 \mathrm{~A} 3)$.
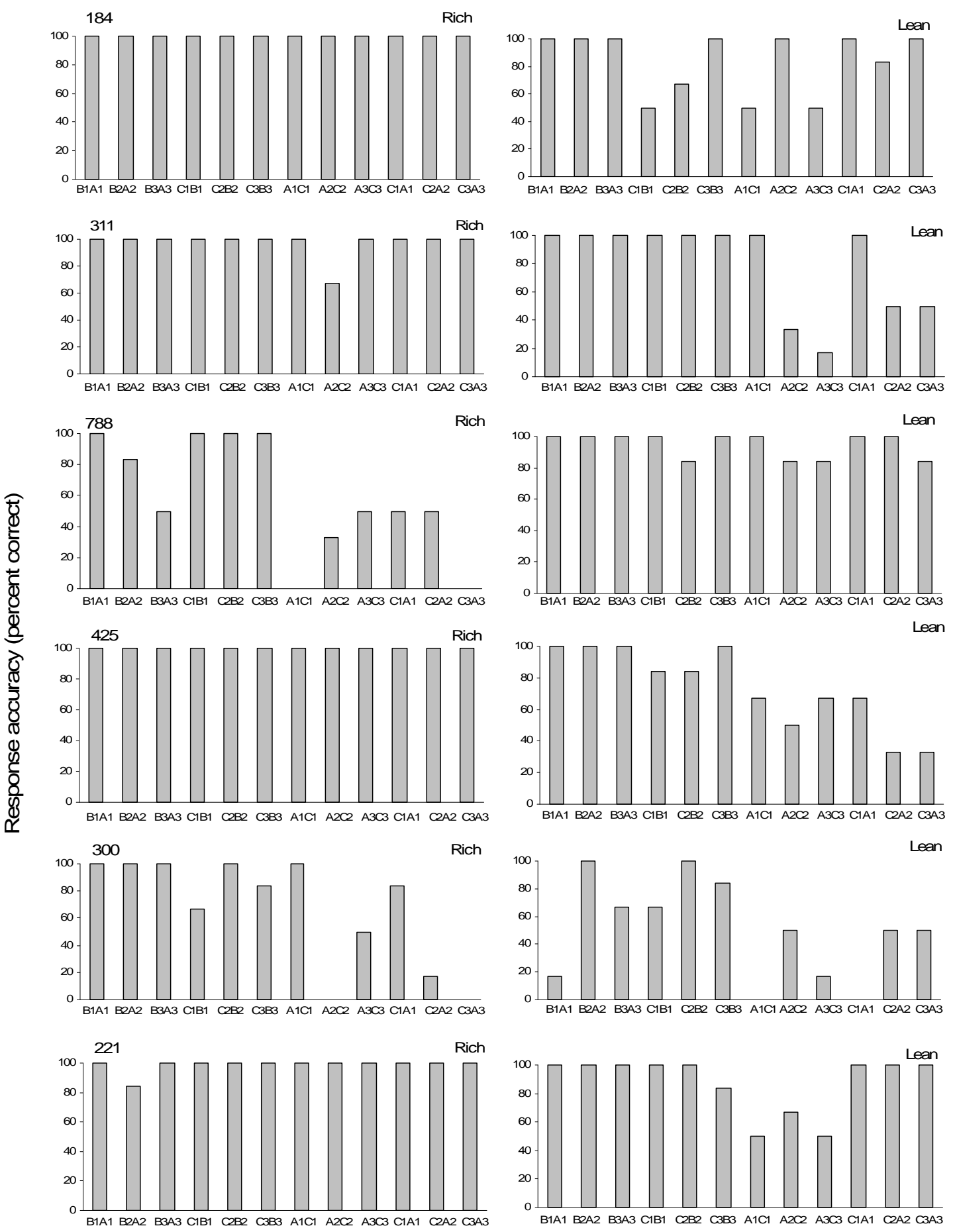

Type of relation 
Figure 3. Percent accuracy on transitivity and combined tests during the first two blocks of testing for each condition and each participant in Experiment 1. Filled bars represent the rich condition; open bars represent the lean condition. Relations represented are AC (transitivity) and CA (combined).
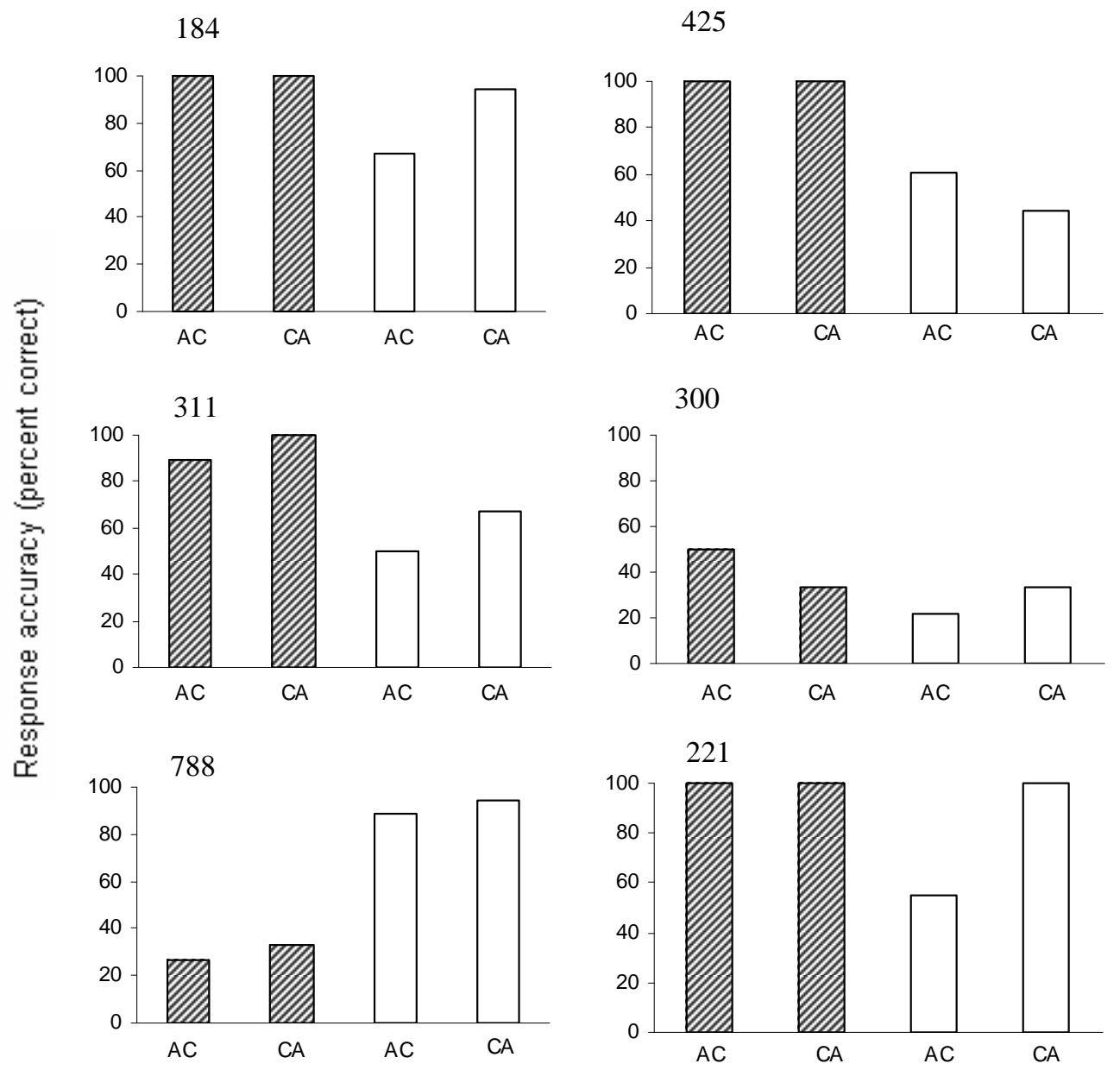

Type of relation 
Figure 4. Percent class-consistent responding in the first two blocks of post-reversal tests for participants 184, 221, and 788 in Experiment 1. The top panel for each participant shows the percent of responses consistent with the original relations (A1B1C1, $\mathrm{A} 2 \mathrm{~B} 2 \mathrm{C} 2$, and $\mathrm{A} 3 \mathrm{~B} 3 \mathrm{C} 3$ ); the bottom panel shows the percent of responses consistent with the stimulus classes formed by reversing the relations (A1B2C2, A2B1C1). Gray bars indicate the relations targeted for disruption by the $\mathrm{AB}$ reversal; white bars indicate control relations.
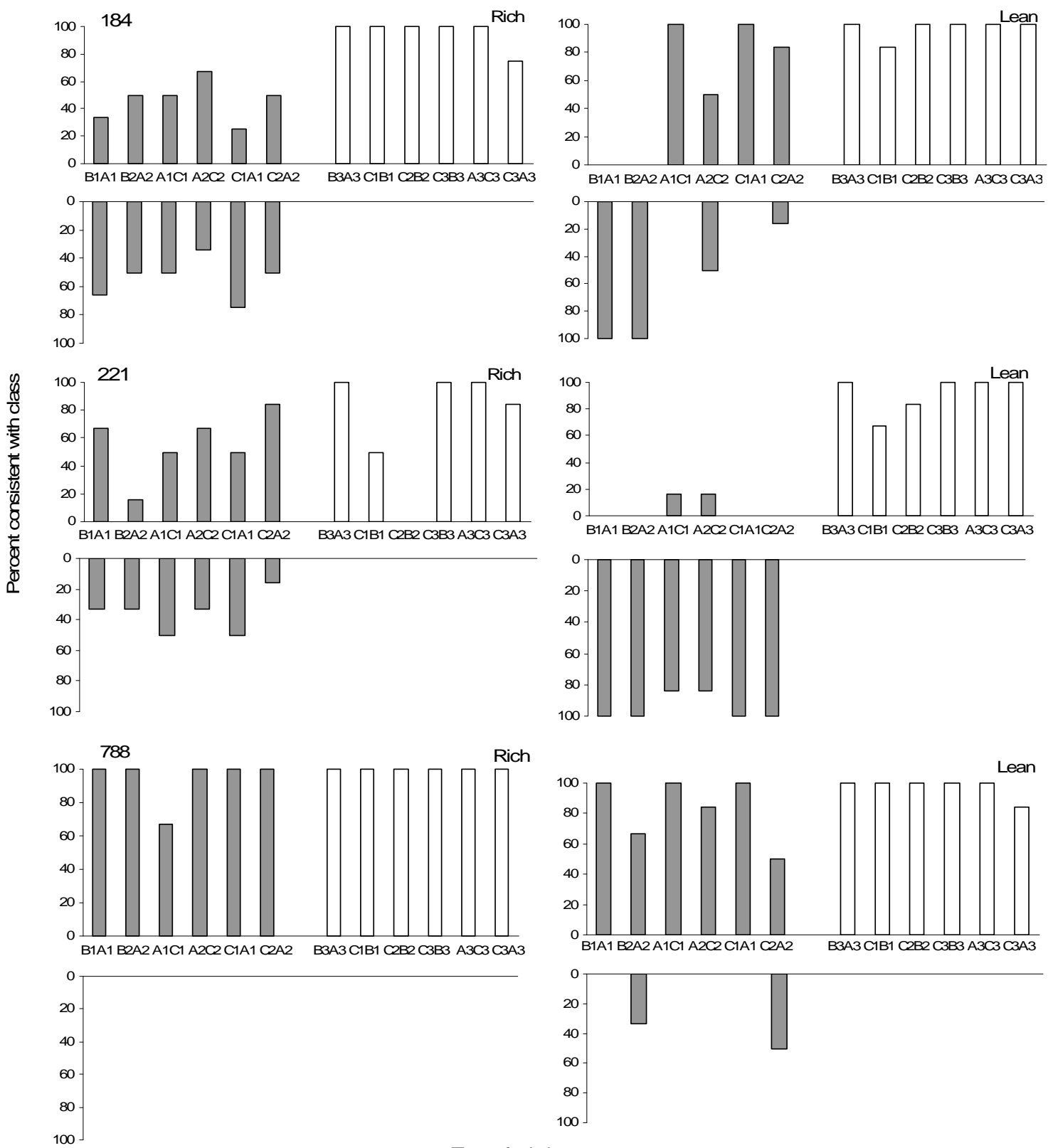

Type of relation 
Figure 5. Percent class-consistent responding in the first two blocks of post-reversal tests for participants 300, 311, and 425 in Experiment 1. Details as in Figure 4.

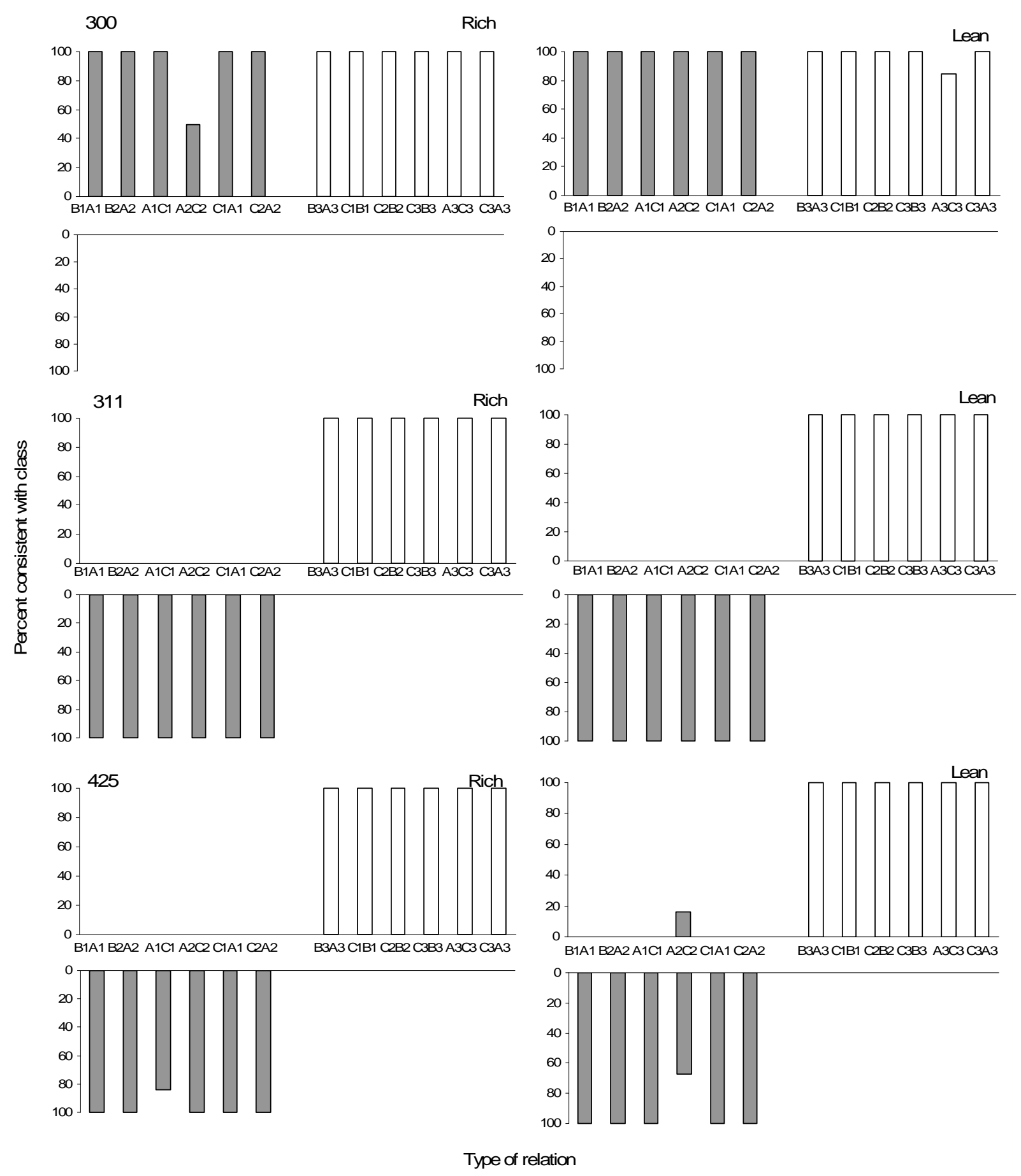


Figure 6. Percent class-consistent responding in the first two blocks of retention tests for participants 184, 221, and 788 in Experiment 1. Details as in Figure 4.
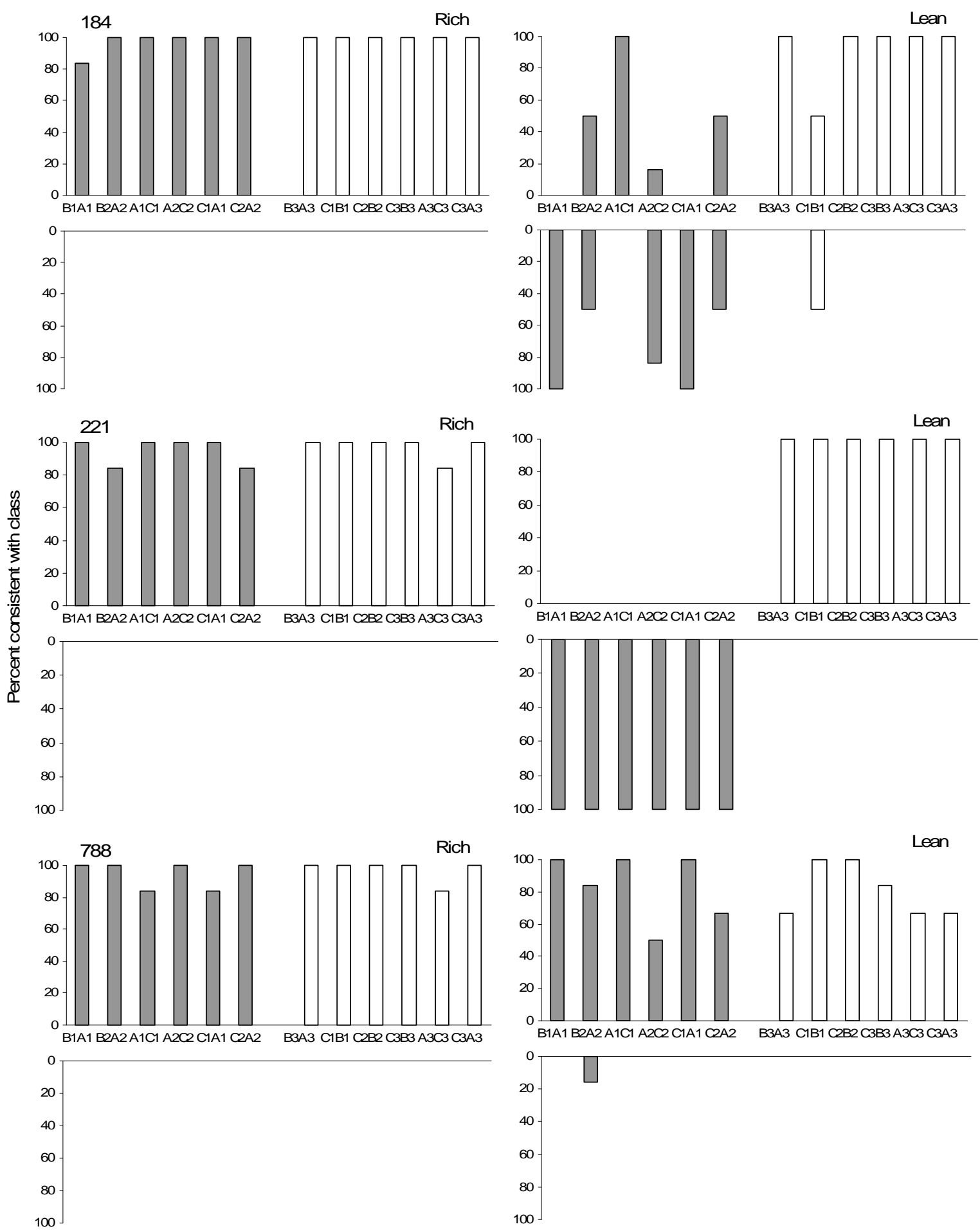

Type of relation 
Figure 7. Percent class-consistent responding in the first two blocks of retention tests for participants 300, 311, and 425 in Experiment 1. Details as in Figure 4.
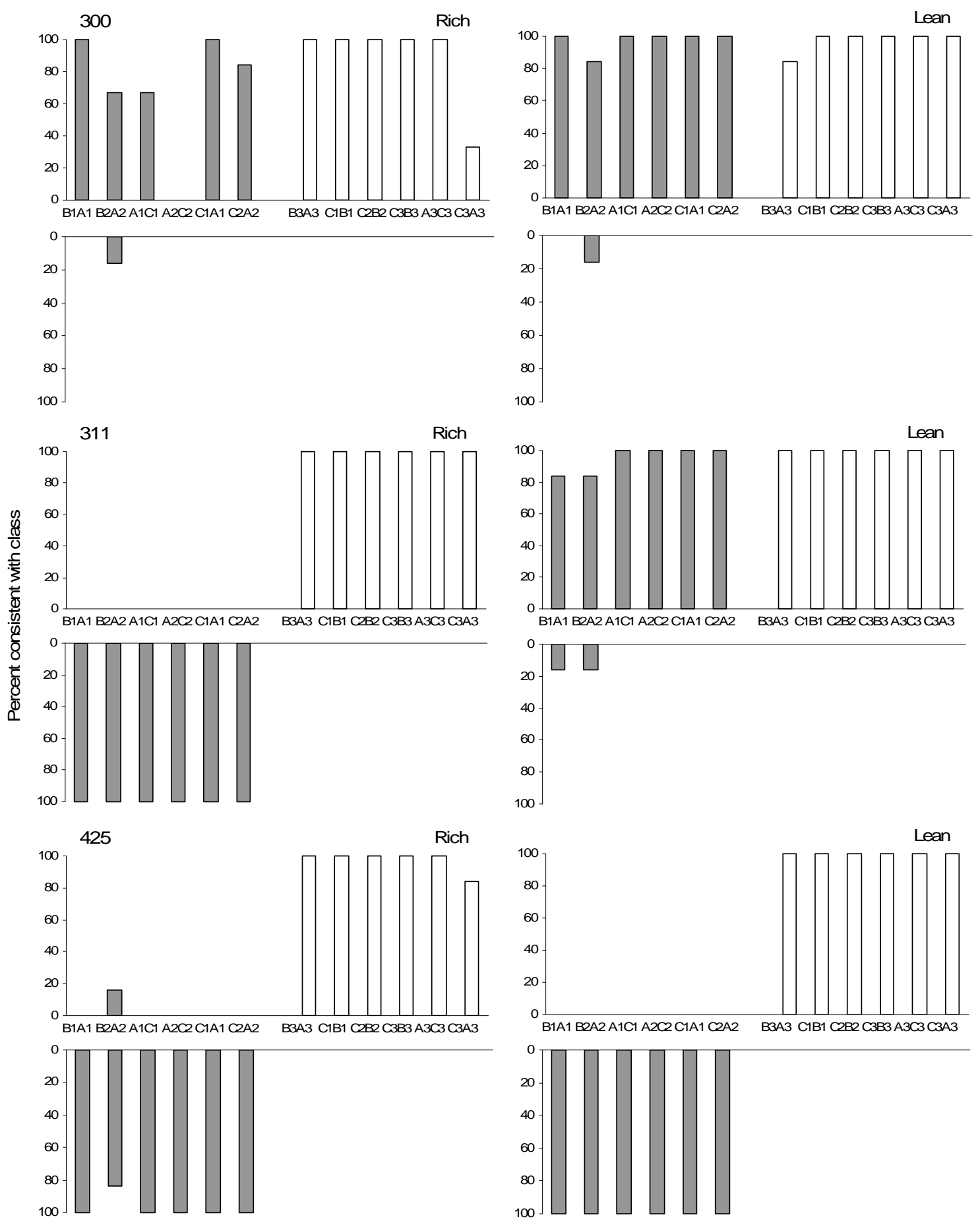

Type of relation 
Figure 8. Percent accuracy on all test trials during the first two blocks of initial testing for each participant in Experiment 2. Types of relations are indicated on the $\mathrm{x}$ axis. Percent of accurate responding is indicated on the y axis.
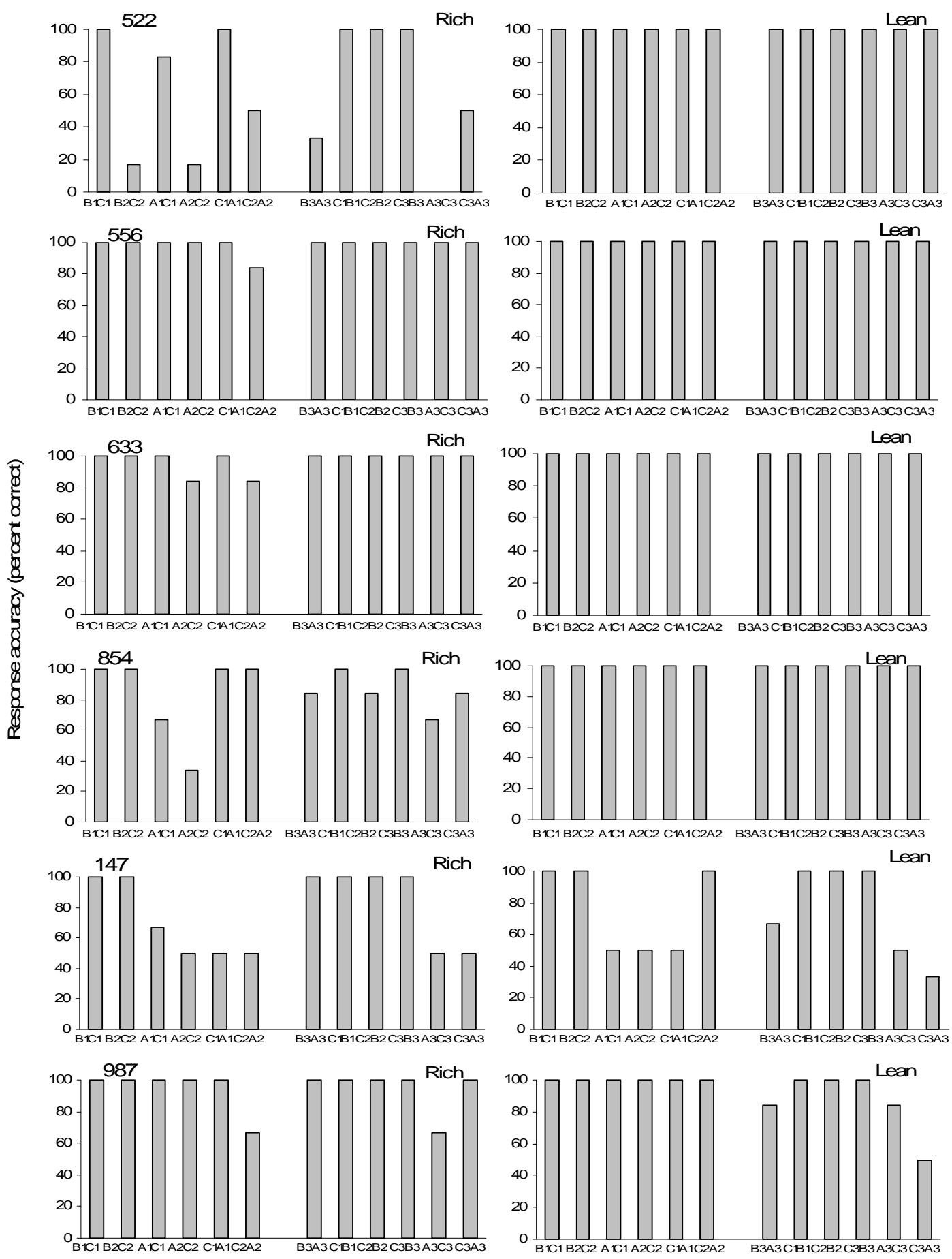

Type of relation 
Figure 9. Percent class-consistent responding during the first two blocks of post-reversal tests for participants 522, 556, 854, and 987 in Experiment 2. Details as in Figure 4.
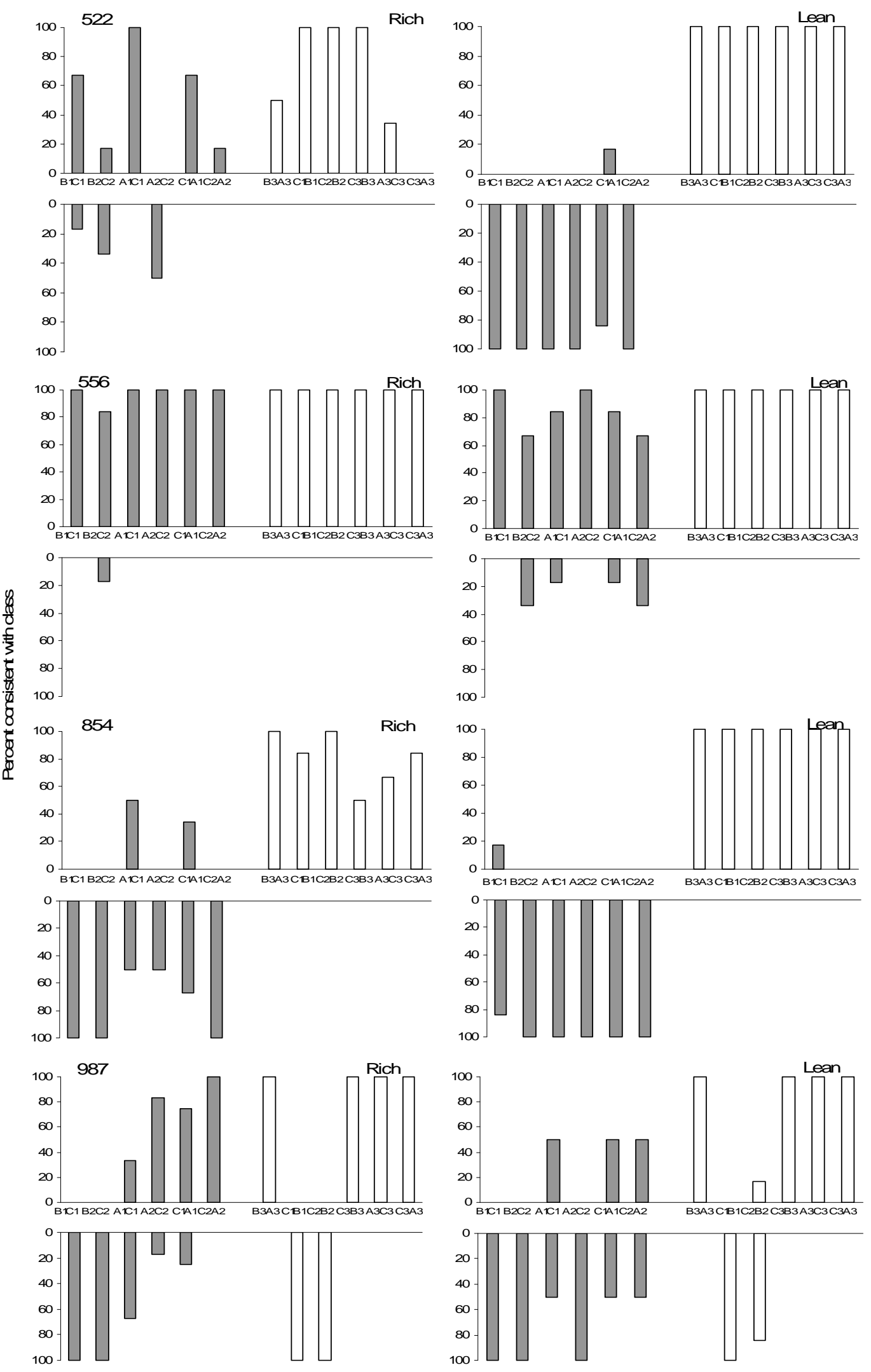

Type of relation 
Figure 10. Percent class-consistent responding during the first two blocks of post-reversal tests for participants 147 and 633 in Experiment 2. Details as in Figure 4.
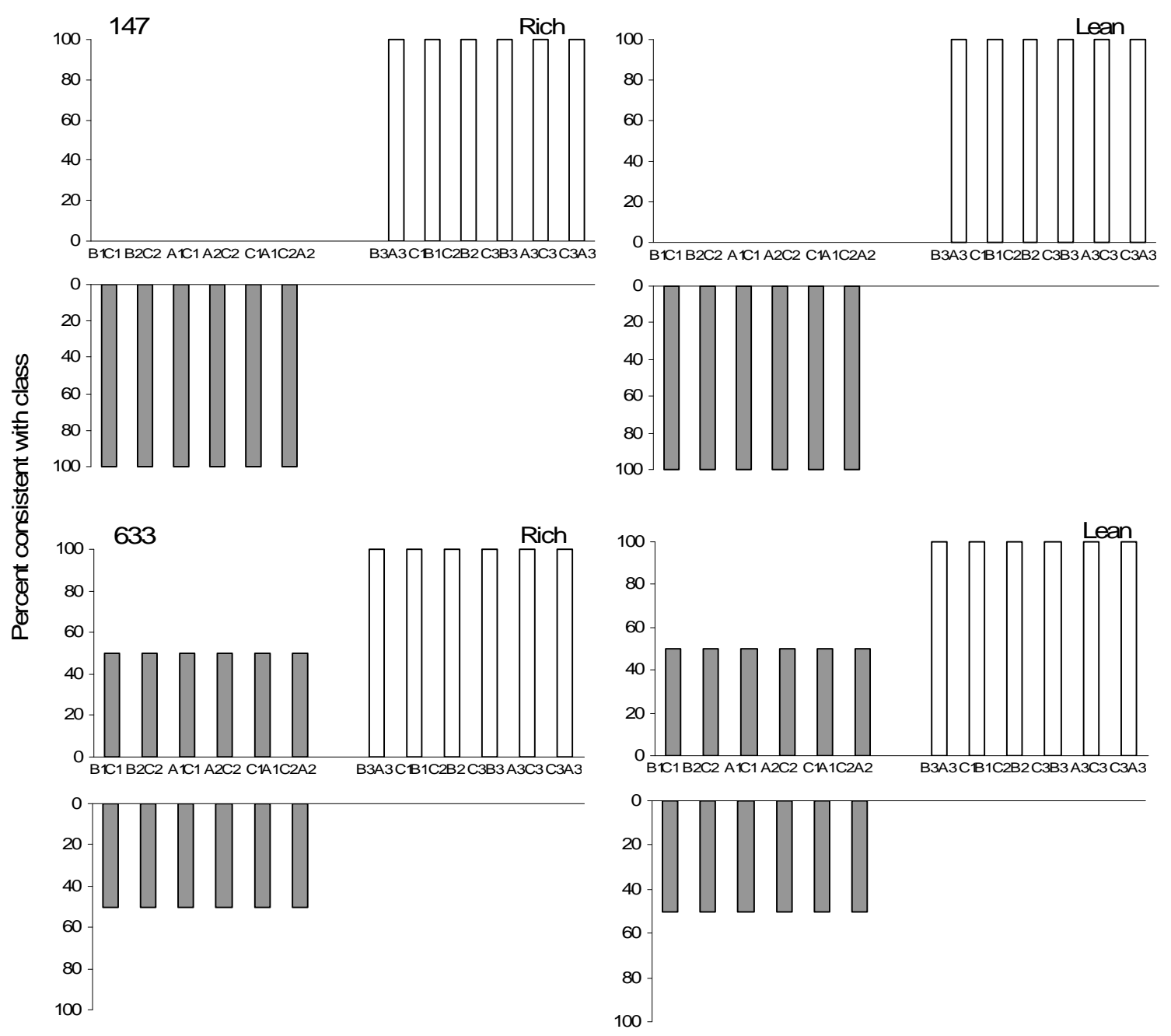

Type of relation 
Figure 11. Percent class-consistent responding during the first two blocks of retention tests for participants 522 and 854 in Experiment 2. Details as in Figure 4.
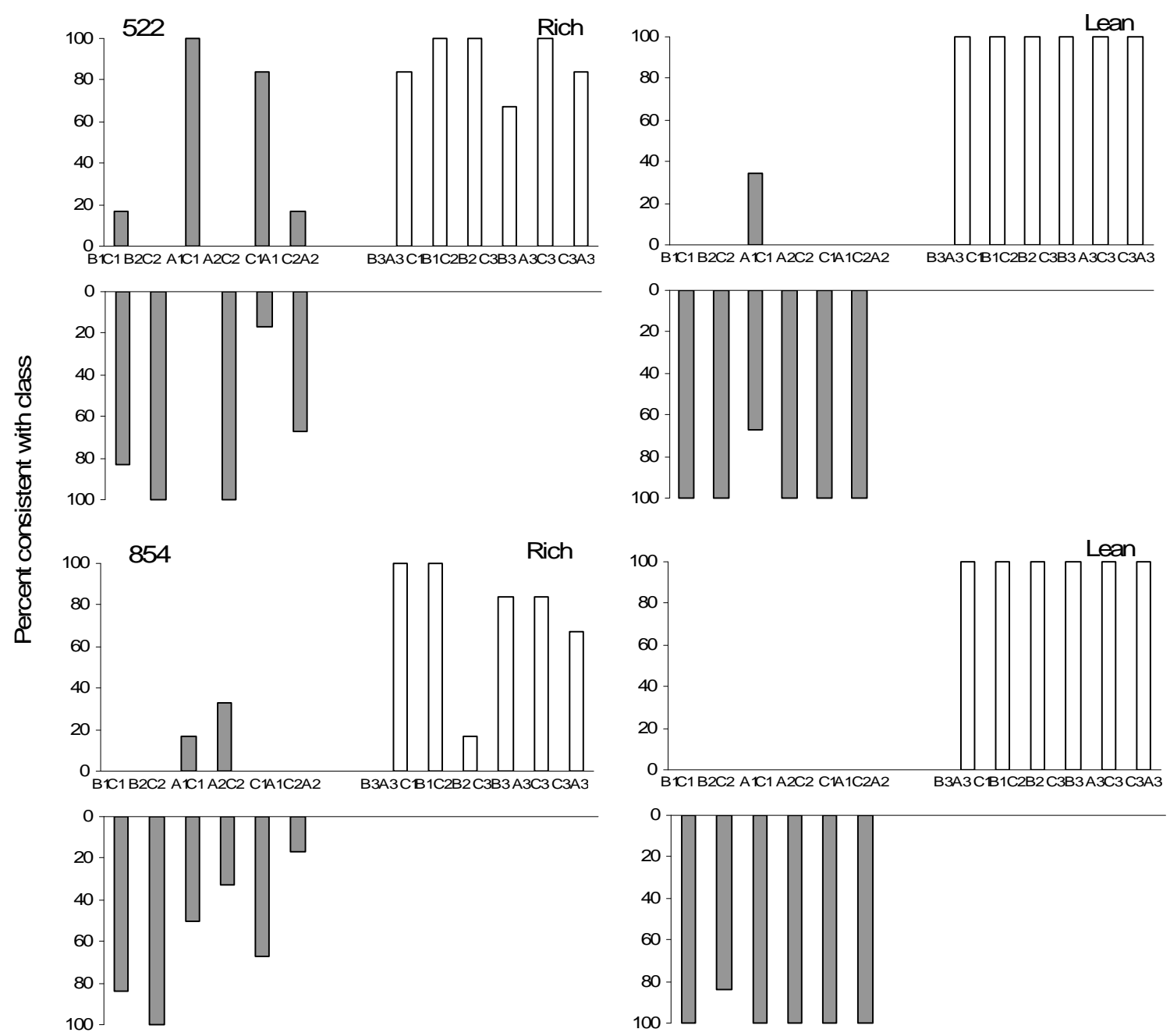

Type of relation 
Figure 12. Percent class-consistent responding during the first two blocks of retention tests for participants 556 and 633 in Experiment 2. Details as in Figure 4.
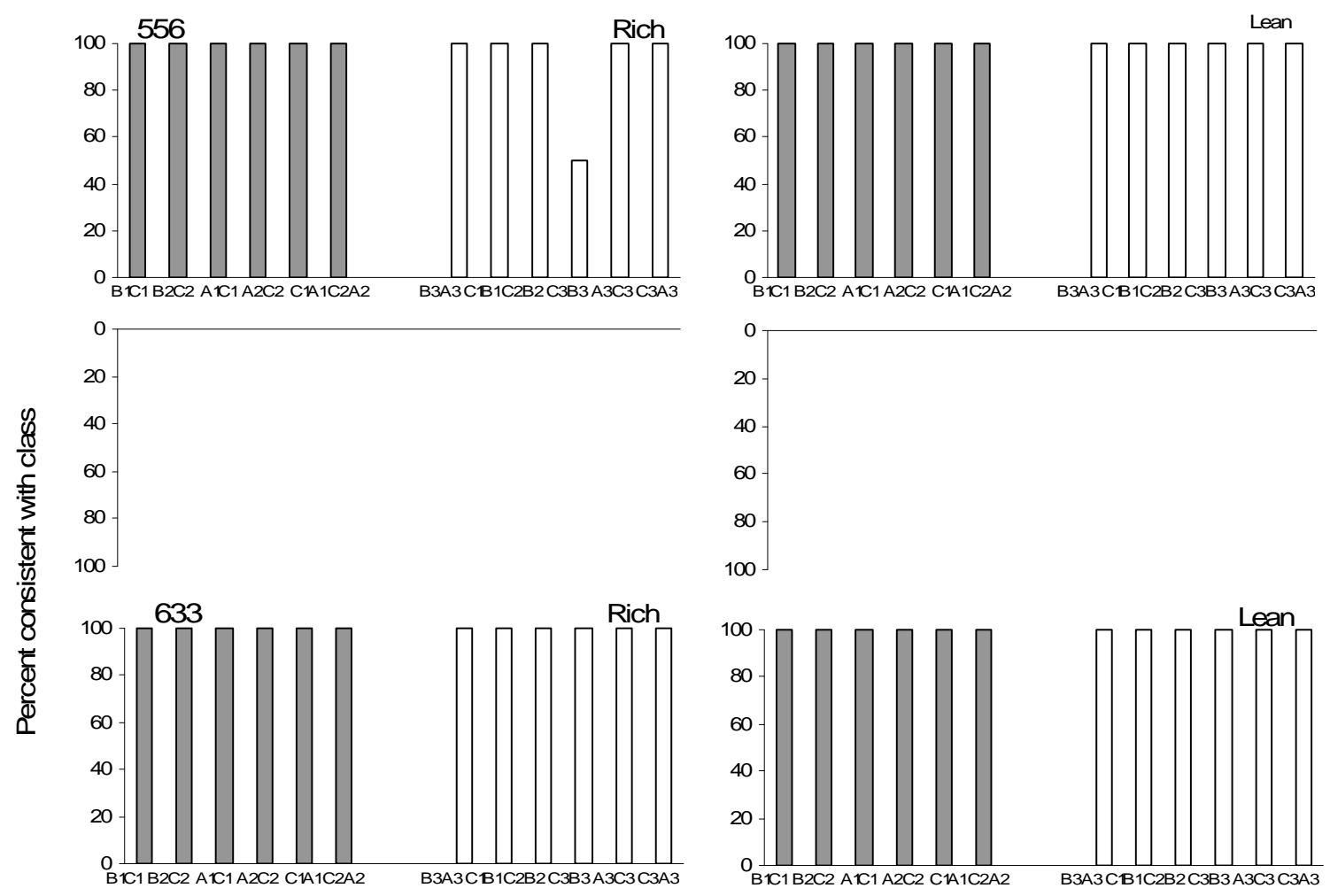

$$
\left.\begin{array}{r}
0 \\
20 \\
40 \\
60 \\
80 \\
100
\end{array}\right]
$$

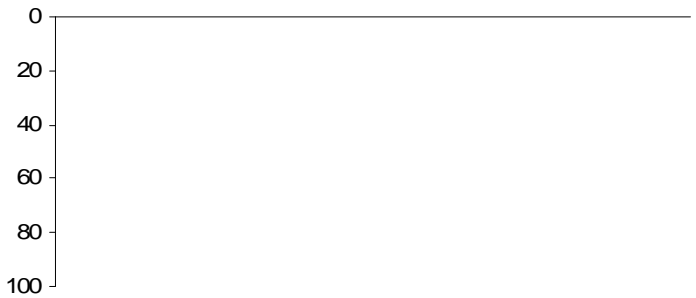

Type of relation 
Figure 13. Percent class-consistent responding during the first two blocks of retention tests for participants 147 and 987 in Experiment 2. Details as in Figure 4.

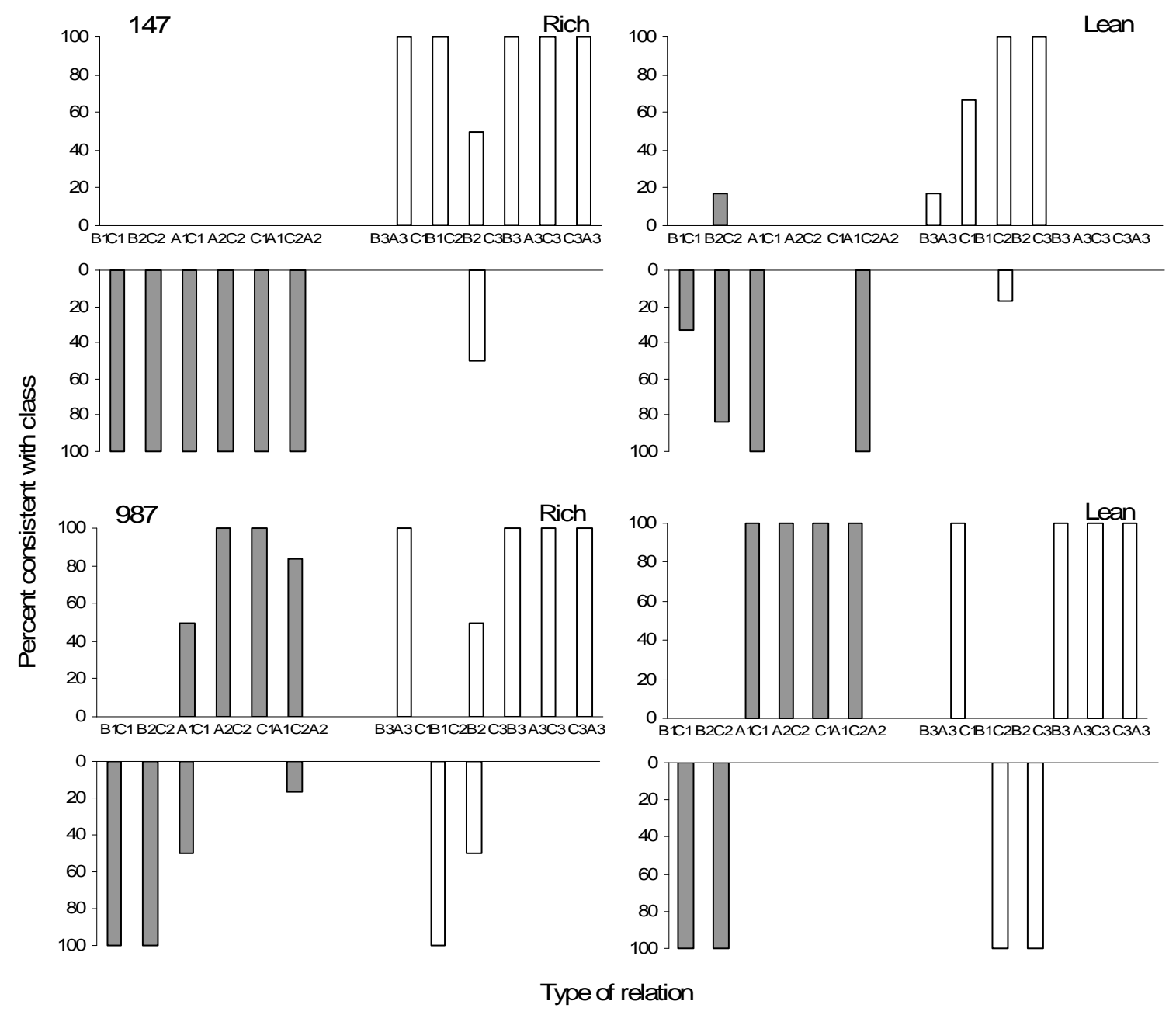


Figure 14. Stimulus sets and classes used in Experiment 3. Letters indicate sets of comparison stimuli; numbers indicate stimulus classes.

Stimulus Set I

\begin{tabular}{|c|c|c|c|c|c|c|}
\hline & 1 & 2 & 3 & 1 & 2 & 3 \\
\hline A & & 龁 & た & 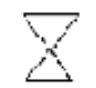 & & \\
\hline B & & & 部 & & $6(0)$ & 空凹 \\
\hline c & & & 鲎 & 10 & پ & 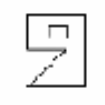 \\
\hline D & 龍卢 & 罒非 & 鬼 & ) & 8 & \begin{tabular}{|l|l|}
0 \\
\end{tabular} \\
\hline$E$ & 3 & 孪 & 竹 & 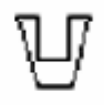 & 局 & , \\
\hline
\end{tabular}

Figure 15. Distracting stimuli used in Experiment 3.

Stimulus Set I


Figure 16. Percent accuracy during the first two blocks of testing for each type of relation: symmetry; transitivity (Trans. 1, 2, and 3 nodes); and combined relations (Comb. 1, 2, and 3 nodes) in Experiment 3. Gray bars represent the rich condition and white bars represent the lean condition.
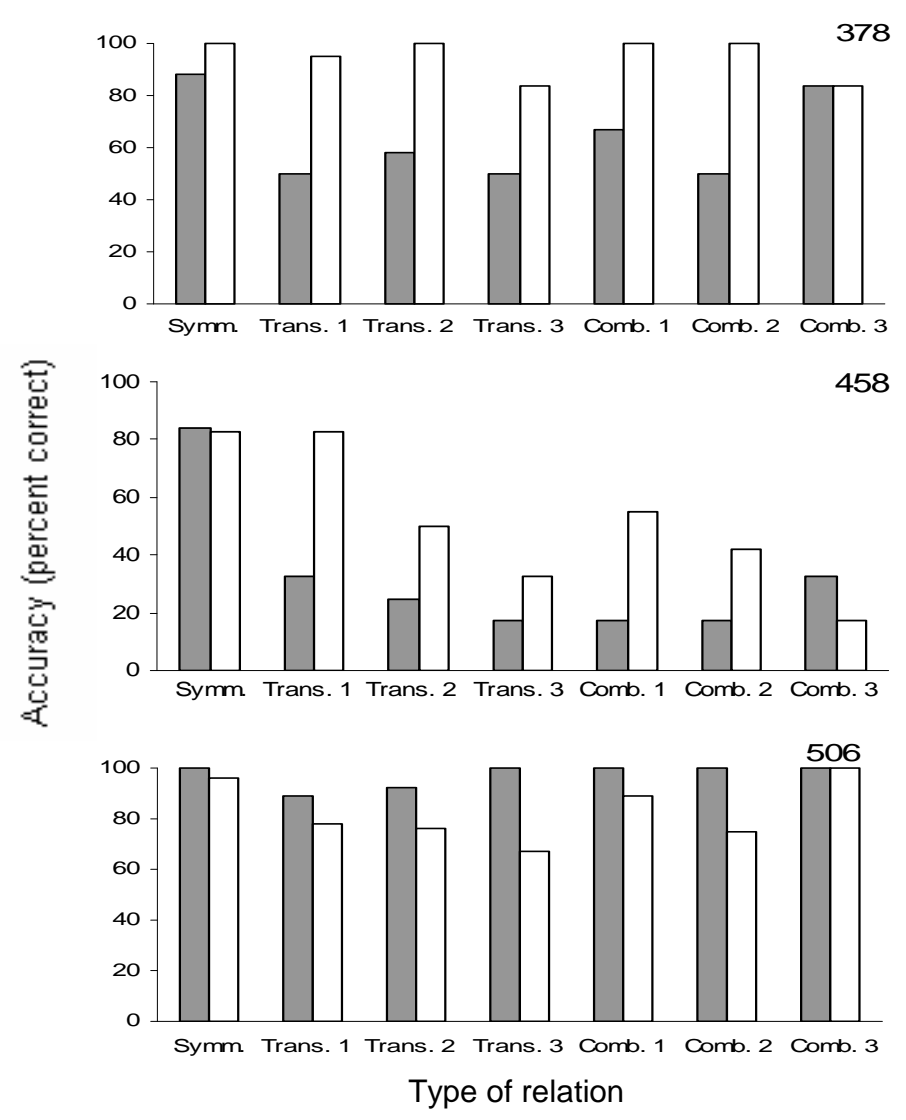

Figure 17. Response speed during the first block of training disruption expressed as proportion of the last block of baseline training in Experiment 3. Gray bars represent the rich condition and white bars represent the lean condition. The horizontal line represents 1.00 proportion of baseline.

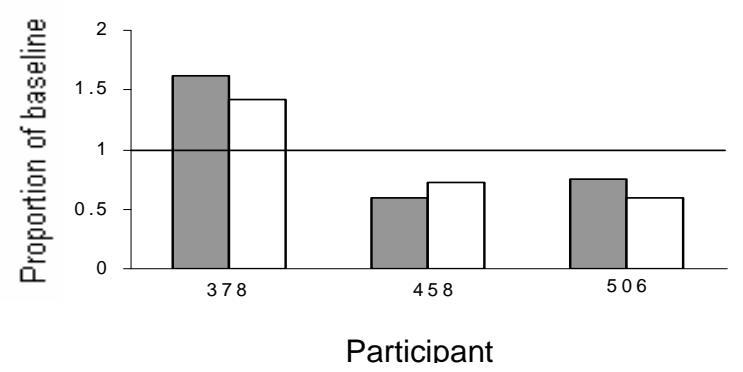


Figure 18. Accuracy during the first block of testing disruption expressed as proportion of the last block of initial testing in Experiment 3. Data are shown for each type of relation: symmetry; transitivity (Trans. 1, 2, and 3 nodes); and combined relations (Comb. 1, 2, and 3 nodes). Gray bars represent the rich condition and white bars represent the lean condition. Note that scales differ across participants. Other details as in Figure 17.

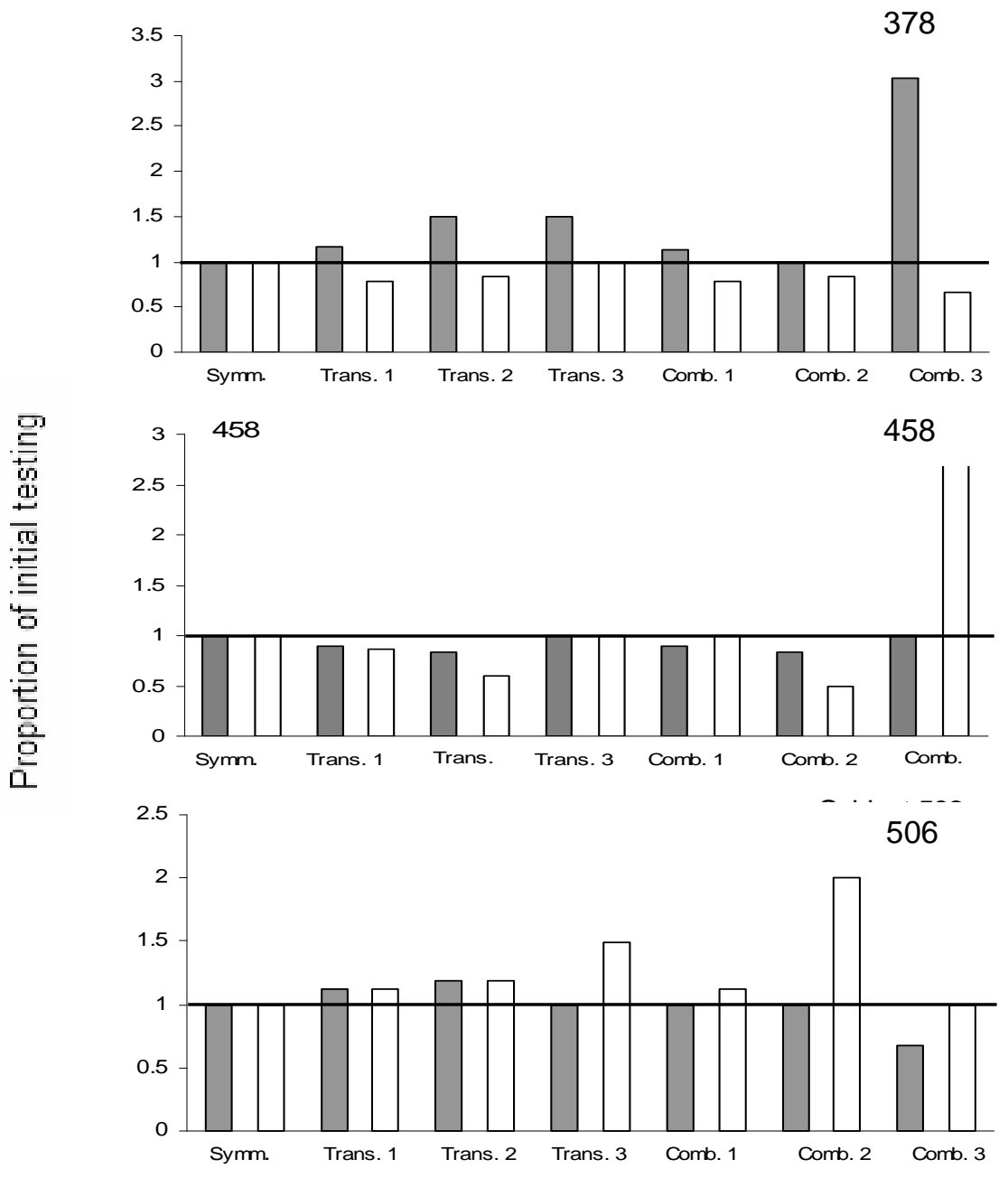

Type of relation 
Figure 19. Percent accuracy during retention tests across conditions by type of relation: symmetry; transitivity (Trans. 1, 2, and 3 nodes); and combined relations (Comb. 1, 2, and 3 nodes) in Experiment 3. Gray bars represent the rich condition and white bars represent the lean condition.
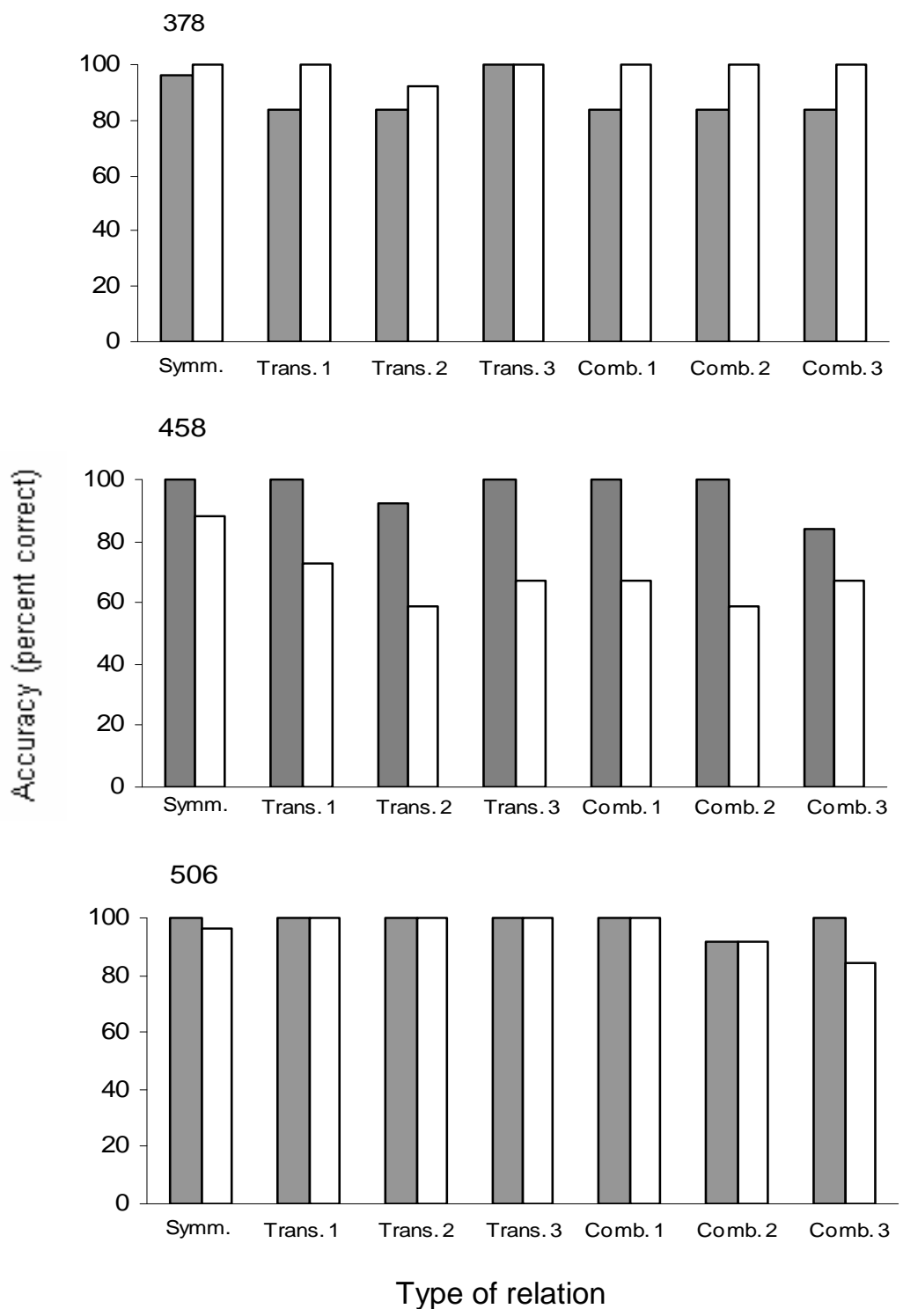


\section{Appendix A}

\section{Participant Recruitment Form}

Here is an opportunity to earn money by participating in a study. We are looking for students to participate in a study examining how feedback affects performance on a problem solving computer game. Participation will require coming to sessions for approximately 8 days. Each session is 40 minutes long. You can earn extra credit for participating in this study, and you will also earn money based on your performance on the game. For more information, contact Marta León at mleonmur@mix.wvu.edu. If you want to participate, sign up below and the experimenter will contact you and arrange the times for the sessions. Thank you.

$\underline{\text { Name }}$

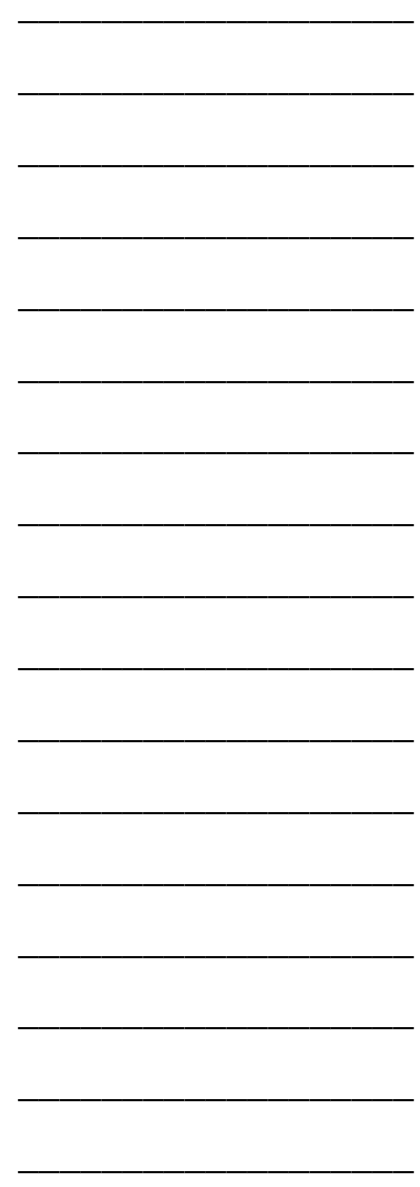

Phone

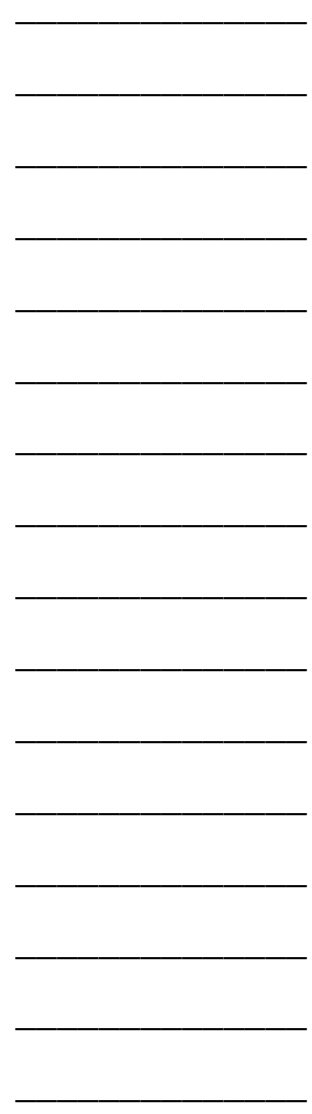

$\underline{\text { Email address }}$

$\underline{\text { Best time to call }}$

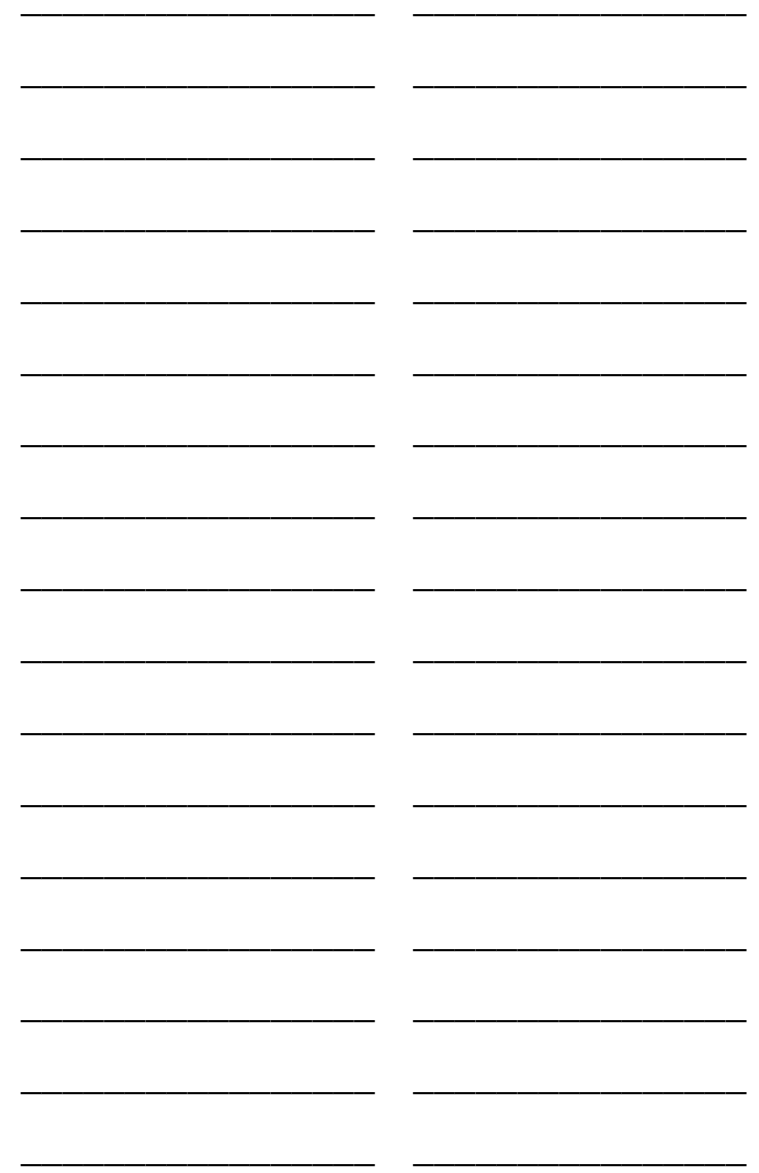




\section{Appendix B}

\section{Information and Consent Form}

\section{$\underline{\text { Introduction }}$}

I, , have been invited to participate in this research study which has been explained to me by Marta León. This research is being conducted to fulfill the requirements for a doctoral dissertation in Psychology at West Virginia University.

\section{Purpose of the study}

The purpose of this study is to learn more about the influence of feedback on problem-solving tasks. I understand that the information collected from my participation in this study might be used in Marta León's dissertation research.

\section{Description of procedures}

This study involves playing several games on the computer. It also entails earning points that will be exchanged for money at the end of the research study. I understand that the number of points I earn will depend on my performance on those games. I have been informed that this study will take approximately eight (8) hours for me to complete. Approximately fifteen (15) students are expected to participate in this study.

\section{$\underline{\text { Financial considerations }}$}

In this research study, I will receive 1 cent for each point I earn on the computer games. I will also receive an attendance bonus of $\$ 1$ for each session I attend. At the end of the study, I will receive a check for the total amount of money earned in all sessions. If for any reason I do not complete all sessions, the money earned before withdrawal will be paid to me.

\section{$\underline{\text { Risks and discomforts }}$}

There are no known or expected risks from participating in this study, except for the mild frustration associated with performance on the computer games.

\section{Alternative}

I understand that I do not have to participate in this study and that I will not experience any type of negative consequences if I decline to participate in the study.

\section{$\underline{\text { Benefits }}$}

I understand that this research study is not expected to be of direct benefit to me, but the knowledge gained may be of benefit to others. The only benefits that I will receive from this study are extra credit points in my course for participation and money contingent on my performance in the computer games.

Page 1 of 2

Initials 


\section{Contact persons}

For more information about this research, I can contact Marta León at mleonmur@mix.wvu.edu, or her supervisor, Dr. Philip N. Chase at 304-293-2001 ext. 31626. For information regarding my rights as a research participant, I may contact the Executive Secretary of the Institutional Review Board at 304-2937073.

\section{Confidentiality}

I understand that any information about me obtained as a result of my participation in this research will be kept as confidential as legally possible. In any publications that result from this research, neither my name nor any information from which I might be identified will be published.

\section{$\underline{\text { Voluntary participation }}$}

Participation in this research study is voluntary. I understand that I am free to withdraw my consent to participate in this study at any time and that such refusal to participate will not affect my student status at West Virginia University or my class standing or grades. Refusal to participate or withdrawal will involve no penalty to me. I have been given the opportunity to ask questions about the research, and I have received answers concerning areas I did not understand. In the event new information becomes available that may affect my willingness to continue to participate in the study, this information will be given to me so I may make an informed decision about my participation.

Upon signing this form, I will receive a copy.

I willingly consent to participate in this research.

Signature of Participant or Participant's Legal Representative

Signature of Investigator or Investigator's Representative
Date

Time

Date

Time

Page 2 of 2 